\title{
Filmes biodegradáveis e agentes de reforço vegetais: Um enfoque em estudos brasileiros sob a ótica da economia circular
}

\author{
Biodegradable films and vegetable reinforcement agents: A focus on Brazilian studies from the \\ perspective of the circular economy \\ Películas biodegradables y agentes de refuerzo vegetales: Un enfoque en estudios brasileños desde \\ la perspectiva de la economía circular
}

Recebido: 14/07/2021 | Revisado: 21/07/2021 | Aceito: 23/07/2021 | Publicado: 31/07/2021

Julia Rabelo Vaz Matheus

ORCID: https://orcid.org/0000-0003-1274-9302 Universidade Federal do Estado do Rio de Janeiro, Brasil Email: juuh.rabelo@hotmail.com

Juliana Martins Satoriva

ORCID: https://orcid.org/0000-0002-8337-9268 Universidade do Estado do Rio de Janeiro, Brasil E-mail: julianasotoriva97@gmail.com

Andreza Salles Barone

ORCID: https://orcid.org/0000-0002-3155-1839 Universidade Federal do Estado do Rio de Janeiro, Brasil E-mail: andreza_salles3@hotmail.com

Cristiano José de Andrade

ORCID: https://orcid.org/0000-0003-0151-5172

Universidade Federal de Santa Catarina, Brasil

E-mail: eng.crisja@gmail.com

Ana Elizabeth Cavalcanti Fai

ORCID: https://orcid.org/0000-0002-8594-2667 Universidade Federal do Estado do Rio de Janeiro, Brasil

Universidade do Estado do Rio de Janeiro, Brasil E-mail: bethfai@yahoo.com.br

\begin{abstract}
Resumo
Antropoceno é a era geológica atual, na qual profundas mudanças ambientais no planeta estão ocorrendo por influência das atividades humanas. Dentre outros aspectos, alguns que corroboram para este cenário são o sistema de produção de alimentos, incluindo o impacto das perdas de alimentos e a geração de resíduos agroindustriais, bem como o consumo e o descarte de plásticos em larga escala, com especial atenção aos materiais com um ciclo de vida curto, a exemplo das embalagens de alimentos. Como consequência, percebe-se uma demanda crescente por embalagens de fontes renováveis e biodegradáveis e, que dessa forma, contribuam para agregar valor e minimizar a perda de alimentos, aumentando sua vida útil e seu valor funcional. Uma alternativa que vem sendo explorada para melhorar as propriedades mecânicas, térmicas e de barreira de filmes é o uso de nanopartículas que, devido a escala nanométrica, fornecem aos filmes características aprimoradas, como maior tensão na ruptura e módulo de elasticidade e menor permeabilidade ao vapor de água quando comparado com filmes biodegradáveis sem o nanoreforço. As nanopartículas podem também ser produzidas a partir de resíduos agroindustriais, como cascas de banana, mandioca, milho, bagaço de uva, semente de manga e resíduos de caju. Assim, esta revisão tem como objetivo discutir criticamente o atual estado da arte e as tendências futuras sobre valorização de vegetais e seus resíduos por meio do desenvolvimento de filmes e embalagens de alimentos mais sustentáveis, com maior enfoque em estudos produzidos por Universidades e outras instituições de pesquisa brasileiras usando matéria-prima nacional.
\end{abstract}

Palavras-chave: Resíduos agroindustriais; Biovalorização; Filmes biodegradáveis; Embalagem ativa; Economia circular; Sustentabilidade.

\footnotetext{
Abstract

Anthropocene is the current geological age in which profound environmental changes on the planet occur under the influence of human activities. Among other aspects, some that corroborate this scenario are the food production system, including the impact of food losses and the generation of agro-industrial residues, as well as the consumption and disposal of plastics on a large scale, with particular attention to materials with a short life cycle, such as food packaging. As a result, there is a growing demand for packaging from renewable sources that are biodegradable and contribute to adding value and minimizing food loss, increasing its shelf life and functional value. An alternative that has been
} 
explored to improve the mechanical, thermal, and barrier properties of films is the use of nanoparticles which, due to the nanometric scale, provide the films with improved characteristics, such as higher tensile strength and Young's modulus and lower vapor permeability of water when compared to biodegradable films without nanoreinforcement. Nanoparticles can also be produced from agro-industrial residues, such as banana, cassava, corn peels, grape pomace, mango seeds and, cashew residues. Thus, this review aims to contribute to knowledge about the valorization of vegetables and their residues through the development of more sustainable films and food packaging, with a greater focus on studies produced by Brazilian institutions using national raw materials.

Keywords: Agro-industrial waste; Biovalorization; Biodegradable films; Active packaging; Circular economy; Sustainability.

\section{Resumen}

El antropoceno es la era geológica actual, en la que se están produciendo profundos cambios ambientales en el planeta bajo la influencia de las actividades humanas. Entre otros aspectos, algunos que corroboran este escenario son el sistema de producción de alimentos, incluyendo el impacto de las pérdidas de alimentos y la generación de residuos agroindustriales, así como el consumo y disposición de plásticos a gran escala, con especial atención a los materiales con un ciclo de vida corto, como el envasado de alimentos. Como resultado, existe una demanda creciente de envases de origen renovable que sean biodegradables y que contribuyan a agregar valor y minimizar la pérdida de alimentos, aumentando su vida útil y valor funcional. Una alternativa que se ha explorado para mejorar las propiedades mecánicas, térmicas y de barrera de las películas es el uso de nanopartículas que, debido a la escala nanométrica, proporcionan a las películas características mejoradas, como mayor resistencia a la tracción y módulo de elasticidad y menor permeabilidad al vapor de agua en comparación con películas biodegradables sin nanorefuerzo. También se pueden producir nanopartículas a partir de residuos agroindustriales, como cáscaras de plátano, mandioca, maíz, orujo de uva, semillas de mango y residuos de anacardo. Así, esta revisión tiene como objetivo contribuir al área de conocimiento sobre la valorización de vegetales y sus residuos a través del desarrollo de películas y empaques de alimentos más sostenibles, con mayor enfoque en estudios producidos por instituciones brasileñas utilizando materias primas nacionales.

Palabras clave: Residuos agroindustriales; Biovaluación; Películas biodegradables; Envasado activo; Economía circular; Sustentabilidad.

\section{Introdução}

O consumo excessivo de recursos naturais e a produção material elevada, em especial de plásticos, são alguns dos maiores desafios contemporâneos. As atividades humanas estão provocando mudanças atmosféricas, geológicas, hidrológicas e biosféricas. Essa influência humana no planeta é o que caracteriza a era geológica atual, denominada de Antropoceno (Velenturf et al., 2021; Willett et al., 2019). Nesse sentido, algumas das atividades que apresentam elevado impacto ambiental negativo são a produção de alimentos (Fanzo et al., 2020; Willett et al., 2019) e o consumo em larga escala de plásticos de origem fóssil (Acquavia et al., 2021).

A cadeia de alimentos é responsável por cerca de 30\% das emissões globais de gases de efeito estufa e $70 \%$ do consumo de água doce. Além disso, agricultura e pastagem ocupam cerca de 40\% da superfície terrestre livre de gelo (Fanzo et al., 2020; Willett et al., 2019). A urgência em transformar o sistema alimentar é reforçada pelas projeções sobre a população mundial que apontam 10 bilhões de pessoas em 2050 (Willett, et al., 2019; Jurgilevich et al., 2016). Além disso, a expressiva perda global de alimentos e geração de resíduos agroindustriais ao longo da cadeia de abastecimento de alimentos também contribuem para impactos negativos no ambiente. Estima-se que o montante de alimentos perdidos represente cerca de $8 \%$ das emissões globais de gases de efeito estufa (FAO, 2015), além de ocupar 0,9 milhão de hectares de solo e consumir $306 \mathrm{~km}^{3}$ de água (FAO, 2014). No entanto, apesar desses aspectos destacados, é importante reforçar a imprescindibilidade de um sistema de produção de alimentos robusto capaz de suprir a demanda alimentar mundial crescente, e de contribuir para a diversificação, preservação e distribuição de alimentos com o apoio da ciência e tecnologia de alimentos (Buckle, 2015).

Somado a esse cenário, outro contribuinte aos impactos ambientais negativos é o crescente consumo e descarte de plásticos de origem petroquímica (Acquavia et al., 2021). Em 2019, cerca de 370 milhões de toneladas de plásticos foram produzidas no mundo (Plasticseurope, 2020). Dentre todos os plásticos produzidos, cerca de 36\% são destinados à elaboração de embalagens plásticas (UNEP, 2018). Considerando a tendência de produção de plástico ao longo dos anos, projeta-se que, em 
2050, serão mais de 25 bilhões de toneladas de plásticos produzidos, cerca de 12 bilhões de toneladas de resíduos plásticos

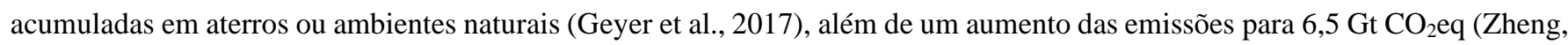
Suh, 2019).

Tendo por base essas estimativas, aumenta a preocupação direcionada em promover impactos positivos que colaborem para reconstituir o meio e melhorar a qualidade de vida de forma geral, forçando os diferentes atores sociais a repensar o modelo tradicional de "descarte" dos materiais gerados comumente relacionado à economia linear (Shogren et al., 2019). Em contraponto, um novo modelo econômico e de desenvolvimento sustentável ganha visibilidade: a economia circular. A Economia Circular é um conceito que repensa as práticas econômicas e objetiva manter produtos, componentes e materiais em circulação tirando proveito do máximo de valor e utilidade entre ciclos técnicos e biológicos, inspirada nos conceitos cíclicos da própria natureza. Em outras palavras: a economia circular propõem um sistema de ciclos de reaproveitamento, em que a maior eficácia desses produtos, componentes e materiais colaboram para tornar o consumo da sociedade mais sustentável, reduzindo, por conseguinte, a emissão de gases do efeito estufa e a geração de resíduos (Murray et al., 2017; Jurgilevich et al., 2016). A indústria de embalagens desempenha um papel crucial nessa mudança de paradigma uma vez que continua a depender majoritariamente de materiais ambientalmente pouco sustentáveis, como plásticos de origem fóssil de uso único e embalagens multicamadas, que representam cerca de 15-20\% de resíduos sólidos em diferentes países (Tako et al., 2021; Hall, 2017; Tencati et al., 2016).

Em 2020, houve aumento de uso de plásticos descartáveis em decorrência das modificações nas atividades humanas durante a pandemia de COVID-19. Por exemplo, o aumento dos sistemas delivery (refeição), e preocupação dos consumidores quanto a higiene e segurança alimentar, propiciou uma demanda crescente do uso de embalagens plásticas descartáveis para alimentos com ciclo de vida curto, especialmente single use, resultando em maior geração de resíduos plásticos (Barone et al., 2021; Silva et al., 2021; Li Mirosa \& Bremer, 2020). Como consequência, evidenciou-se um retrocesso de agendas ambientais globais como o "Compromisso Global para a Nova Economia dos Plásticos". Muitas das políticas destinadas a limitar produtos plásticos de uso único foram revertidas e o desenvolvimento de embalagens de fontes renováveis, biodegradáveis e compostáveis é urgente, como parte das ações para conter a poluição plástica (Barone et al., 2021; Ellen Macarthur Foundation, 2021).

Imbuída no contexto de embalagens que circulem de forma positiva nos nossos sistemas, - design circular do berço ao berço - as tendências de mercado apontam para o desenvolvimento de embalagens biodegradáveis a partir de excedentes vegetais e resíduos agroindustriais, principalmente para o segmento de embalagens de alimentos (Matheus et al., 2021a; Meys et al., 2020; Luttenberger, 2019). De modo geral, diversos consumidores estão dispostos a escolher embalagens sustentáveis, mesmo apresentando maior preço de mercado que os plásticos convencionais (Shen et al., 2020). Um exemplo recente é o Ifood que lançou uma seção de embalagens sustentáveis direcionada aos restaurantes (Ifood Regenera) com parceria da Já fui mandioca, uma empresa brasileira de embalagens à base de amido de mandioca (FORBES, 2021).

Nessa circunstância, a crescente busca por polímeros ambientalmente amigáveis aliada à necessidade de aproveitar melhor os resíduos alimentares contribuem para o interesse no desenvolvimento de filmes biodegradáveis (Acquavia et al., 2021). A formação de filmes a partir de resíduos alimentares vegetais ocorre devido à presença de polímeros naturais nessas matrizes, tais como amido, gelatina/proteína e compostos lignocelulósicos (Acquavia et al., 2021; Brito, Ferreira \& Fai, 2020), sendo o amido um dos biopolímeros mais representativos para o mercado de bioplásticos (Shen et al., 2020). Ademais, o uso desses resíduos ricos em componentes com atividade antimicrobiana e antioxidante, na formulação de filmes biodegradáveis, pode expandir a aplicabilidade para a produção de embalagem ativa de alimentos visto que essas embalagens ativas podem atuar como veículo para carrear compostos bioativos que possivelmente irão interagir com o alimento embalado, incrementando sua qualidade nutricional e prolongando sua vida de prateleira (Soofi et al., 2021; Bhardwaj, Alam \& Talwar, 2019).

Outro aspecto que tem ganhado destaque na área de filmes biodegradáveis é o uso da nanotecnologia como uma estratégia para o desenvolvimento de materiais mais resistentes. As nanopartículas apresentam maior capacidade de reforçar 
filmes quando comparadas com seus equivalentes em maior escala devido à sua maior proporção de aspecto. Essas características favorecem a aplicação das nanopartículas na área de embalagem de alimentos (Theivasanthi et al., 2018), em especial, nos biopolímeros, melhorando a resistência mecânica e térmica, a aparência, a transparência e as propriedades de barreira dos filmes (Soofi et al., 2021). Celulose é um dos biopolímeros mais estudados para elaboração de nanopartículas com aplicação na área de embalagem (Wróblewska-Krepsztul et al., 2018). Nanoceluloses podem ser obtidas a partir de diferentes resíduos agroindustriais, tais como bagaço de uva (Coelho et al., 2018), coroa de abacaxi (Faria et al., 2020) e casca de banana (Pelissari et al., 2014), e serem aplicadas para reforçar filmes, como filmes à base de amido reforçados com nanocristais de celulose do bagaço de uva (Coelho et al., 2020), nanofibras de celulose da casca de banana (Pelissari et al., 2017) e da coroa de abacaxi (Balakrishnan et al., 2017). Esses estudos reforçam a viabilidade de aproveitar os resíduos agroindustriais vegetais que seriam descartados para a produção de filmes com potencial característica de biodegradabilidade.

Por fim, ressalta-se a vocação agrícola brasileira de produção de vegetais com matrizes químicas diversificadas e a possibilidade de aproveitamento desses para obtenção de filmes biodegradáveis evitando perdas pós-colheita e o descarte de resíduos sob a perspectiva da economia circular. Assim, considerando esse contexto, o objetivo desta revisão é discutir criticamente o atual estado da arte e as tendências futuras sobre valorização de vegetais e seus resíduos através do desenvolvimento de filmes e embalagens para alimentos que sejam mais sustentáveis. Neste trabalho, buscou-se dar um enfoque aos estudos produzidos por Universidades e outras instituições de pesquisa brasileiras utilizando vegetais nativos ou cultivados em abundância no país.

\section{Metodologia}

Foi realizada uma revisão de natureza bibliográfica com abordagem qualitativa, realizada através da pesquisa de artigos científicos indexados nas bases de dados eletrônicos Pubmed, Web of Science, Scopus e Google Scholar. Os critérios de inclusão foram: artigos com disponibilidade na íntegra e que apresentam coesão com a temática do estudo em tela, com enfoque para aqueles que se relacionam à produção de filmes biodegradáveis e agentes de reforço a partir de vegetais e seus resíduos desenvolvidos em Universidade e outras instituições de pesquisa brasileiras nos últimos 5 anos.

\section{Perda e Desperdício de Alimentos: Importância do Aproveitamento de Resíduos Vegetais}

Atualmente, a perda de alimentos constitui-se um problema global (Laso et al., 2021; Corrado et al., 2017), promovendo elevada geração de resíduos alimentares, além de impactos ambientais, socioeconômicos e na saúde de populações (Arun et al., 2020; Teigiserova et al., 2019). Não há uma definição consensual em relação a este termo, mas uma das mais difundidas é a da FAO (2011) que considera como perda de alimentos a perda não intencional na quantidade ou qualidade de alimentos destinados ao consumo humano durante a colheita, manuseio, transporte e armazenamento (antes do consumo). Por outro lado, o desperdício de alimentos refere-se a alimentos seguros e nutritivos para consumo humano que são descartados ou não consumidos, principalmente nas etapas de varejo e consumo (UNEP, 2021; FAO, 2011).

A perda alimentar mundial por ano é de cerca de 1,3 bilhão de toneladas, considerando toda a cadeia de abastecimento alimentar, o que representa quase um terço de todos os alimentos produzidos para consumo humano (Gustavsson, 2011). Um dos grupos alimentares que se destaca pelas perdas é o de tubérculos, frutas e hortaliças, uma vez que compreendem cerca de 40 a 50\% das perdas (FAO, 2019). Dados recentes sobre desperdício alimentar estimam que, em 2019, foram gerados cerca de 931 milhões de toneladas de resíduos alimentares nos domicílios (61\%), serviços de alimentação (26\%) e varejo (13\%) (UNEP, 2021). Especificamente no Brasil, o desperdício alimentar per capita e familiar gera anualmente cerca de 42 e $129 \mathrm{~kg}$ de resíduos, respectivamente (Porpino et al., 2018). Além disso, na indústria de alimentos há geração de cerca de 140 bilhões de toneladas de resíduos anualmente (Zuin \& Ramin, 2018). Esses resíduos são, na maioria das vezes, subutilizados, embora apresentem uma 
rica e heterogênea composição química (Jiménez-Moreno et al., 2020; Fidelis et al., 2019), apresentando significativos teores de proteínas, lipídios, amido, fibras alimentares, micronutrientes e bioativos (Brito, Ferreira \& Fai, 2020; Faustino et al., 2019; Banerjee et al., 2017).

A necessidade de reduzir a perda de alimentos e a geração de resíduos alimentares é preconizada em algumas metas dos Objetivos de Desenvolvimento Sustentável (ODS) da Organização das Nações Unidas, em especial a submeta 12.3 e 12.5 (ONU, 2015). No entanto, dificilmente esses resíduos serão totalmente erradicados, uma vez que são inerentes ao processamento de alimentos. Em vista disso, é fundamental desenvolver estratégias de aproveitamento desses resíduos por meio de práticas sustentáveis e tecnologias verdes, que estejam alinhadas com a economia circular e o desenvolvimento sustentável, propiciando benefícios socioeconômicos, ambientais e nutricionais (Souza et al., 2020a; Lemaire \& Limbourg, 2019).

Atualmente, resíduos agroindustriais podem ser utilizados na produção de ração animal, biocombustível, compostos bioativos, enzimas, entre outros bioprodutos (Sharma et al., 2021; Velarde et al., 2020; Takeyama et al., 2020; Mendes et al., 2020) sendo, uma promissora alternativa o uso desses resíduos para desenvolvimento de filmes biodegradáveis (Luchese et al., 2021; Luchese et al., 2019) e filmes nanocompósitos (Coelho et al., 2020; Pelissari et al., 2017; Balakrishnan et al., 2017) com potencial aplicação como embalagem ativa (Crizel et al., 2018; Crizel et al., 2016). Nesse sentido, considerando a proeminente geração de resíduos alimentares no Brasil (Santos et al., 2020; Dal' Magro \& Talamini, 2019), tais como resíduos de acerola, goiaba, abacaxi, caju, uva, laranja, mamão, maracujá, mandioca (Takeyama et al., 2020; Andrade et al., 2017; Silva et al., 2014; Souza et al., 2011), há potencialidade de valorização destes resíduos vegetais para o desenvolvimento de filmes, dado riqueza de componentes hábeis para formação de uma matriz polimérica (Souza et al., 2021; Acquavia et al., 2021; Otoni et al., 2017). A Figura 1 ilustra dados obtidos por instituições brasileiras sobre filmes à base de vegetais e seus resíduos. 
Figura 1. Diferentes partes de vegetais e seus resíduos explorados para o desenvolvimento de filmes por Universidades e outras instituições de pesquisa brasileiras.

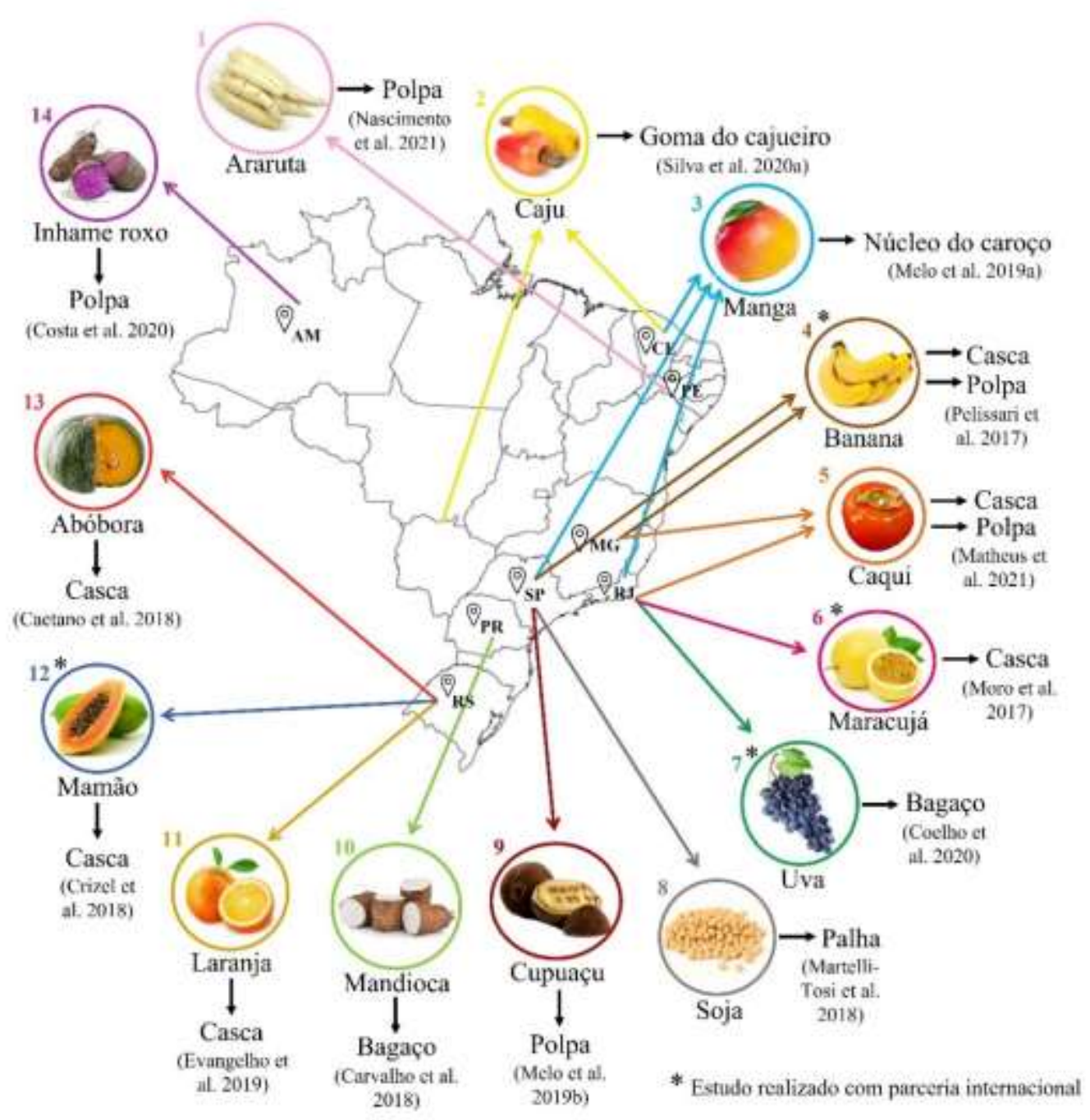

Setas com cores iguais correspondem ao mesmo estudo realizado em parceria entre diferentes instituiçōes nacionais
1 Universidade Federal de Pernambuco (PE)/ Centro de Pesquisa Agropecuária do Trópico Semiárido (PE)

2 Universidade Federal do Ceará (CE)/ Embrapa Agroindústria Tropical (CE)/ Embrapa Instrumentaçăo (SP)

Universidade Federal do Ceará (CE)/ Embrapa Agroindústria Tropical (CE)/ Embrapa Agroindústria de Alimentos (RJ)/ Embrapa Instrumentação (SP)

Universidade Federal dos Vales do Jequitinhonhu e Mucuri (MG)/ Universidade de São Paulo (SP)/ Universidade Estadual de Campinas (SP) Universidad Nacional de Colombia (Colồmbia)

5 Universidade Federal do Estado do Rio de Janeiro (RJ)/ Universidade do Estado do Rio de Janeiro (RJ) / Universidade Federal dos Vales do Jequitinhonha e Mucuri (MG)

Universidade Federal Rural do Rio de Janeiro (RJ)/ Embrapa Agroindústria de Alimentos RJV Universidad Zamorano (Honduras)

Universidade Federal do Rio de Janciro (RDV/ Pontifieia Universidade Católica do Rio de Janeiro (RJ) Embrapa Agroindústria de Alimentos (RJ)/ Centro Brasileiro de Pesquisas Fisicas (RJ)/ Universidade do Minho (Portugal)

8 Universidade de São Paulo (SP) Embrapa Instrumentação (SP)

Universidade Estadual Paulista (SP) Universidade Estadual de Campinas (SP)

10 Universidade Federal do Paraná (PR)/ Universidade Estadual de Maringà (PR)

11 Universidade Federal de Pelotas (RS)/ Universidade de Passo Fundo (RS)

Universidade Federal do Rio Grande do Sul (RS)/ Universidade de Lisboa e Instituto Português do Mar e da Atmosfera (Portugal)

13 Universidade Federal do Rio Grande do Sul (RS)

Universidade Federal do Amazonas (AM) 


\section{Biopolímeros Extraídos de Resíduos Agroindustriais: Matéria-Prima para Elaboração de Filmes}

Os principais biopolímeros extraídos de vegetais e seus resíduos para produção de bioplásticos e de filmes biodegradáveis, além de proteínas, são amido, compostos lignocelulósicos e pectina (Figura 2) (Ranganathan et al., 2020; Sharmila, 2020). O amido é um polissacarídeo formado basicamente por moléculas de amilose (cadeias longas e lineares) e amilopectina (curtas e ramificadas), que consistem em cadeias de D-glicose unidas por ligações glicosídicas $\alpha$ (1-4) nas cadeias principais e ligações glicosídicas $\alpha$ (1-6) nos pontos de ramificação. Os grânulos de amido são semicristalinos devido ao arranjo desses biopolímeros lineares e ramificados, onde os pontos de ramificação são distribuídos para formar lamelas amorfas e cristalinas. De modo geral, as caraterísticas do grânulo de amido são dependentes das diferentes fontes genotípicas e apresentarão distintas propriedades físico-químicas e funcionais (Chisenga et al., 2019). Portanto, é imprescindível compreender as características e propriedades do amido para seu melhor aproveitamento.

Filmes à base de amido com elevado conteúdo de amilose tendem a formar estruturas mais quebradiças e com maior resistência devido à formação de uma rede mais rígida e compacta na matriz do filme (Fu et al., 2018), conferindo uma maior propriedade de barreira e tensão na ruptura (Silva et al., 2019). Por outro lado, a amilopectina atua aumentando a plasticidade dos filmes (Martins et al., 2020). A formação de filmes coesos de amido, pode requerer a aplicação de tratamentos no amido (como aquecimento e cisalhamento) para romper sua estrutura semicristalina. Ademais, o uso de plastificantes, como glicerol, pode ser necessário para formação de uma matriz contínua e melhora das propriedades mecânicas, uma vez que interferem na ligação de hidrogênio (Acquavia et al., 2020; Maraveas, 2020) e na interação macromolecular durante o rearranjo da amilopectina ou amilose (Fu et al., 2018). O amido de diferentes fontes vegetais e seus resíduos foram explorados para a elaboração de filmes, tais como amido de mandioca (Luchese et al., 2021; Huang et al., 2020), de arroz (Suriyatem et al., 2018), de quinoa (Pagno et al., 2015), de milho (Luchese et al., 2019), de araruta (Nascimento et al., 2021; Nogueira et al., 2019), de batata (Balakrishnan et al., 2017), de semente de jaca (Costa et al., 2021), semente de manga (Silva et al., 2019), de polpa de banana (Pelissari et al., 2017) e de polpa de maçã (Tirado-Gallegos et al., 2018).

Os compostos lignocelulósicos, que constituem as fibras naturais, apresentam uma composição dependente de sua fonte vegetal (Maraveas, 2020), sendo os principais componentes a celulose (35-50\%), a hemicelulose (20-35\%) e a lignina (10-25\%) (Chong et al., 2020). A pectina, polissacarídeo amplamente presente nos resíduos agroindustriais, também é considerada uma matéria-prima relevante para a área de biopolímeros (Mellinas et al., 2020). A valorização de resíduos vegetais para o desenvolvimento de filmes pode ocorrer a partir da extração de compostos lignocelulósicos da polpa de amora (Wang et al., 2017), da palha de soja (Martelli-Tosi et al., 2017), da casca de batata (Shruthy \& Preetha, 2019), dos resíduos do processamento de suco de cenoura (Sogut \& Cakmak, 2020) e também a partir da extração de pectina das cascas de frutas, como melancia (Guo et al., 2021), limão (Rodsamran \& Sothornvit, 2019a) e abacaxi (Rodsamran \& Sothornvit, 2019b). Além disso, muitas vezes, vegetais e seus resíduos são integralmente incorporados em formulações de filmes, sem necessariamente extrair biopolímeros específicos. Brito et al. (2019) observaram a interação entre diferentes componentes (proteína, celulose, pectina e amido) que foram responsáveis pela formação da rede polimérica em filmes à base de farinha de resíduos de vegetais e frutas. O uso de purê de mamão (Rodríguez et al., 2020) e de caqui (Matheus et al., 2021b) em formulações de filmes favoreceram a formação da matriz polimérica em decorrência aos carboidratos totais presentes. Assim, os diferentes componentes contribuem de forma conjunta para a formação da matriz polimérica.

A forma de incorporação de resíduos agroindustriais nas formulações filmogênicas pode influenciar diretamente nas propriedades dos filmes desenvolvidos. Luchese et al. (2021) estudaram a influência da forma de incorporação de resíduos do processamento de laranja nas propriedades de filmes à base de amido. O filme adicionado de resíduos sob a forma de extrato aquoso apresentou maior solubilidade em água e menor rigidez do que o filme adicionado de resíduos de laranja em pó. Sugeriuse que as fibras do resíduo em pó atuaram como agentes de reforço no filme de amido, aumentando sua rigidez e reduzindo sua 
flexibilidade. Similarmente, Jirukkakul (2016) comparou as propriedades mecânicas e de barreira de filmes à base de banana sob a forma de farinha e de purê. O autor concluiu que o uso de farinha resultou em filmes com maior resistência, elongação e propriedade de barreira, provavelmente devido ao aumento das ligações de hidrogênio entre as cadeias de amido.

Ademais, as propriedades dos filmes podem ser afetadas de acordo com a técnica de produção. O método casting, além de ser mais compatível com a escala laboratorial, é o mais empregado em filmes à base de frutas e vegetais dado a termosensibilidade inerente desses componentes (Yepes et al., 2019; Otoni et al., 2017). Por outro lado, a extrusão possibilita a produção de bioplásticos em maior volume (Chen et al., 2020) e, ainda, pode afetar positivamente a estrutura de polímeros como o amido (Fitch-Vargas et al., 2016). Yepes et al. (2019) observaram que a extrusão seguida de termocompressão gerou filmes à base de amido e proteína de lentilha com maior tensão na ruptura e menor permeabilidade ao vapor de água do que os filmes desenvolvidos pela técnica de casting.

A Tabela 1 apresenta dados recentes produzidos em instituições brasileiras acerca do aproveitamento de vegetais e/ou resíduos agroindustriais para a produção de filmes.

Figura 2. Principais biopolímeros extraídos de resíduos agroindustriais vegetais para formulação de filmes biodegradáveis.

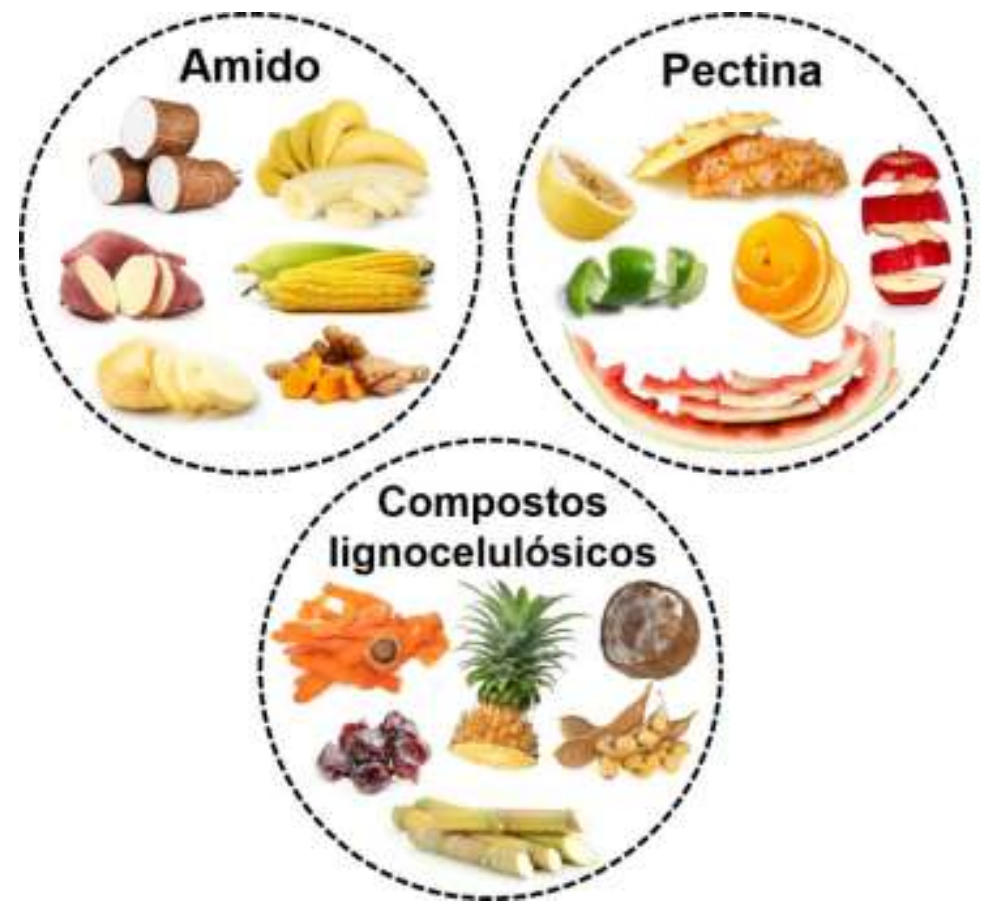

Fonte: Autores. 


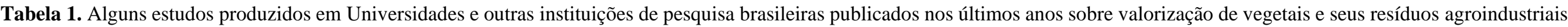
para o desenvolvimento de filmes com diferentes funcionalidades e aplicações.

\begin{tabular}{|c|c|c|c|c|c|c|c|c|}
\hline $\begin{array}{l}\text { Vegetal (nome } \\
\text { científico) }\end{array}$ & $\begin{array}{l}\text { Parte } \\
\text { utilizada do } \\
\text { vegetal } \\
\end{array}$ & $\begin{array}{l}\text { Pré- } \\
\text { tratamento }\end{array}$ & $\begin{array}{l}\text { Polímero de } \\
\text { base e outros } \\
\text { aditivos } \\
\end{array}$ & $\begin{array}{l}\text { Técnica de } \\
\text { produção do } \\
\text { filme } \\
\end{array}$ & $\begin{array}{l}\text { Análise de } \\
\text { bioatividade }\end{array}$ & $\begin{array}{l}\text { Aplicação } \\
\text { como embalagem de alimento }\end{array}$ & Filiação dos autores & REF \\
\hline $\begin{array}{l}\text { Abóbora (Cucurbita } \\
\text { maxima e Cucurbita } \\
\text { moschata) }\end{array}$ & Casca & Extrato & $\begin{array}{l}\text { Amido de } \\
\text { Mandioca e óleo } \\
\text { essencial de } \\
\text { orégano }\end{array}$ & Casting & $\begin{array}{l}\text { Atividade } \\
\text { antioxidante e } \\
\text { antimicrobiana }\end{array}$ & $\begin{array}{l}\text { A aplicação dos filmes ativos desenvolvidos } \\
\text { como embalagem proporcionaram proteção } \\
\text { contra oxidação lipídica de amostras de carne } \\
\text { moída até o } 3^{\circ} \text { dia de armazenamento } \\
\text { refrigerado. }\end{array}$ & $\begin{array}{l}\text { Universidade Federal do } \\
\text { Rio Grande do Sul }\end{array}$ & 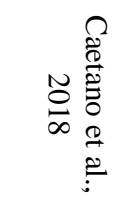 \\
\hline $\begin{array}{l}\text { Acerola (Malpighia } \\
\text { punicifolia L.) }\end{array}$ & \multirow{3}{*}{ Polpa } & \multirow{3}{*}{ Polpa } & \multirow{3}{*}{$\begin{array}{l}\text { Amido de } \\
\text { mandioca e } \\
\text { glicerol }\end{array}$} & \multirow{3}{*}{ Casting } & \multirow{3}{*}{$\begin{array}{l}\text { Atividade } \\
\text { antioxidante }\end{array}$} & \multirow{3}{*}{$\begin{array}{l}\text { Azeite de dendê embalado em filmes } \\
\text { adicionados das polpas de frutas apresentou } \\
\text { menor oxidação lipídica durante os } 40 \text { dias de } \\
\text { armazenamento em comparação com os } \\
\text { controles. Observou-se um efeito diretamente } \\
\text { proporcional entre a adição de polpa nas } \\
\text { formulações e o efeito antioxidante dos filmes } \\
\text { ativos. }\end{array}$} & \multirow{3}{*}{$\begin{array}{l}\text { Faculdade de Tecnologia } \\
\text { SENAI, Universidade } \\
\text { Tiradentes e Universidade } \\
\text { Federal da Bahia }\end{array}$} & \multirow{3}{*}{ 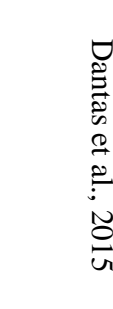 } \\
\hline $\begin{array}{l}\text { Manga (Mangifera } \\
\text { indica } L .)\end{array}$ & & & & & & & & \\
\hline $\begin{array}{l}\text { Seriguela (Spondias } \\
\text { purpurea) }\end{array}$ & & & & & & & & \\
\hline \multirow{2}{*}{$\begin{array}{l}\text { Amendoim (Arachis } \\
\text { hypogaea) }\end{array}$} & \multirow{2}{*}{ Casca } & \multirow{3}{*}{ Extrato } & \multirow{3}{*}{$\begin{array}{l}\text { Quitosana e } \\
\text { glicerol }\end{array}$} & \multirow{3}{*}{ Casting } & \multirow{3}{*}{$\begin{array}{l}\text { Atividade } \\
\text { antioxidante e } \\
\text { antimicrobiana }\end{array}$} & \multirow{3}{*}{$\begin{array}{l}\text { Os extratos favoreceram o desenvolvimento de } \\
\text { filmes ativos com maior capacidade de } \\
\text { proteção contra oxidação lipídica de amostras } \\
\text { de frango comparado ao filme controle (sem } \\
\text { extratos) durante } 7 \text { dias de refrigeração. Além } \\
\text { disso, as contagens de psicotróficos foram } \\
\text { significativamente menores para as amostras } \\
\text { embaladas com os filmes ativos, sendo está } \\
\text { propriedade associada somente à presença da } \\
\text { quitosana. }\end{array}$} & \multirow{3}{*}{$\begin{array}{l}\text { Universidade de São } \\
\text { Paulo, Universidade } \\
\text { Federal de São Paulo, } \\
\text { Universidade Federal de } \\
\text { São Carlos e Universidad } \\
\text { Central del Ecuador }\end{array}$} & \multirow{3}{*}{ 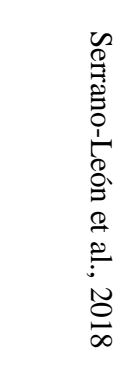 } \\
\hline & & & & & & & & \\
\hline $\begin{array}{l}\text { Pimenta rosa (Schinus } \\
\text { terebinthifolius Raddi) }\end{array}$ & $\begin{array}{l}\text { Caules, } \\
\text { folhas e } \\
\text { polpas } \\
\text { rejeitadas }\end{array}$ & & & & & & & \\
\hline $\begin{array}{l}\text { Amora-preta (Morus } \\
\text { Nigra L.) }\end{array}$ & Polpa & Extrato & $\begin{array}{l}\text { Carboximetilcel } \\
\text { ulose e glicerol }\end{array}$ & Casting & $\begin{array}{l}\text { Atividade } \\
\text { antioxidante }\end{array}$ & $\begin{array}{l}\text { Tomates cerejas revestidos por imersão em } \\
\text { solução filmogênica à base de extrato de } \\
\text { amora-preta apresentaram resultados positivos } \\
\text { quanto a perda de peso e firmeza dos frutos } \\
\text { durante } 15 \text { dias de armazenamento. No entanto, } \\
\text { atributos visuais e sensoriais dos tomates } \\
\text { revestidos com solução filmogênica foram } \\
\text { afetados negativamente. }\end{array}$ & $\begin{array}{l}\text { Instituto Federal de } \\
\text { Educação, Ciência e } \\
\text { Tecnologia de Santa } \\
\text { Catarina, Universidade de } \\
\text { Campinas e Centro } \\
\text { Universitário Unifacvest }\end{array}$ & 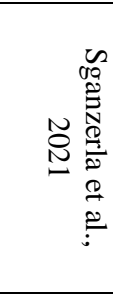 \\
\hline $\begin{array}{l}\text { Banana (Musa } \\
\text { cavendishii Lamb.) }\end{array}$ & Polpa & Purê & $\begin{array}{l}\text { Pectina e } \\
\text { glicerol }\end{array}$ & Casting & Não avaliada & Não avaliada & Embrapa Instrumentação & 요= \\
\hline
\end{tabular}


Research, Society and Development, v. 10, n. 9, e49210918278, 2021

(CC BY 4.0) | ISSN 2525-3409 | DOI: http://dx.doi.org/10.33448/rsd-v10i9.18278

\begin{tabular}{|c|c|c|c|c|c|c|c|c|}
\hline Banana (Musa spp.) & Casca & Farinha & \multirow[t]{2}{*}{$\begin{array}{l}\text { Amido de milho } \\
\text { e glicerol }\end{array}$} & \multirow[t]{2}{*}{ Casting } & \multirow[t]{2}{*}{$\begin{array}{l}\text { Atividade } \\
\text { antioxidante }\end{array}$} & \multirow[t]{2}{*}{ Não avaliada } & \multirow[t]{2}{*}{$\begin{array}{l}\text { Universidade Federal de } \\
\text { Minas Gerais }\end{array}$} & \multirow{2}{*}{ 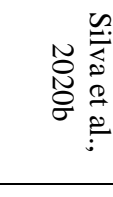 } \\
\hline $\begin{array}{l}\text { Nêspera (Eriobotrya } \\
\text { japonica) }\end{array}$ & Folha & Extrato & & & & & & \\
\hline Banana (Musa spp.) & Casca & Farinha & $\begin{array}{l}\text { Amido de milho } \\
\text { e glicerol }\end{array}$ & Casting & Não avaliada & Não avaliada & $\begin{array}{l}\text { Universidade Federal de } \\
\text { Minas Gerais }\end{array}$ & 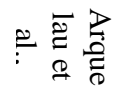 \\
\hline $\begin{array}{l}\text { Banana verde (Musa } \\
\text { paradisiaca) }\end{array}$ & $\begin{array}{l}\text { Polpa } \\
\text { (extração do } \\
\text { amido) }\end{array}$ & $\begin{array}{l}\text { Solução } \\
\text { aquosa }\end{array}$ & $\begin{array}{l}\text { Amido de } \\
\text { banana verde, } \\
\text { glicerol e } \\
\text { micropartículas } \\
\text { de lipídeos } \\
\text { sólidos } \\
\text { contendo ácido } \\
\text { ascórbico } \\
\end{array}$ & Casting & $\begin{array}{l}\text { Atividade } \\
\text { antioxidante }\end{array}$ & Não avaliada & $\begin{array}{l}\text { Universidade de } \\
\text { Campinas }\end{array}$ & 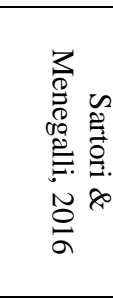 \\
\hline $\begin{array}{l}\text { Batata doce roxa } \\
\text { (Ipomoea Batatas L.) }\end{array}$ & $\begin{array}{l}\text { Casca } \\
\text { (extração de } \\
\text { antocianina) }\end{array}$ & Pó liofilizado & $\begin{array}{l}\text { Quitosana, } \\
\text { álcool } \\
\text { polivinílico e } \\
\text { extrato de }\end{array}$ & Casting & Não avaliada & $\begin{array}{l}\text { Filmes usados como embalagem inteligente } \\
\text { apresentaram mudanças colorimétricas visíveis } \\
\text { frente à modificação do valor de pH da carne } \\
\text { embalada por } 3 \text { dias. A incorporação de casca } \\
\text { de jabuticaba nos filmes destacou-se como um }\end{array}$ & $\begin{array}{l}\text { Universidade Federal de } \\
\text { Santa Catarina }\end{array}$ & 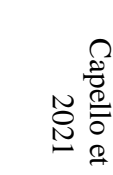 \\
\hline $\begin{array}{l}\text { Jabuticaba (Plinia } \\
\text { caulifora) }\end{array}$ & & & antocianina & & & $\begin{array}{l}\text { indicador colorimétrico sensível ao } \mathrm{pH} \text { para } \\
\text { monitorar o frescor de carnes. }\end{array}$ & & \\
\hline $\begin{array}{l}\text { Beterraba (Beta } \\
\text { vulgaris L.) }\end{array}$ & $\begin{array}{l}\text { Resíduos } \\
\text { (cascas, talos } \\
\text { e aparas) }\end{array}$ & Pó & $\begin{array}{l}\text { Resíduo de } \\
\text { cápsula de } \\
\text { gelatina de } \\
\text { origem bovina }\end{array}$ & Casting & $\begin{array}{l}\text { Atividade } \\
\text { antioxidante }\end{array}$ & $\begin{array}{l}\text { Filmes à base de resíduos foram mais eficientes } \\
\text { quando comparados ao filme controle (sem } \\
\text { resíduo de beterraba) na proteção de amostras } \\
\text { de óleo de girassol contra o processo de } \\
\text { oxidação primária ao longo de } 35 \text { dias de } \\
\text { armazenamento. }\end{array}$ & $\begin{array}{l}\text { Universidade Federal do } \\
\text { Rio Grande do Sul }\end{array}$ & 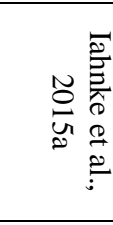 \\
\hline \multirow{2}{*}{$\begin{array}{l}\text { Café verde (Coffea } \\
\text { arabica } \mathrm{L} .)\end{array}$} & Grão verde & Óleo & \multirow{2}{*}{$\begin{array}{l}\text { Carboximetilcel } \\
\text { ulose, glicerol e } \\
\text { lecitina }\end{array}$} & \multirow{2}{*}{ Casting } & \multirow{2}{*}{$\begin{array}{l}\text { Atividade } \\
\text { antioxidante }\end{array}$} & \multirow{2}{*}{ Não avaliada } & \multirow{2}{*}{$\begin{array}{l}\text { Universidade Federal do } \\
\text { Rio de Janeiro, } \\
\text { Universidade Federal do } \\
\text { Estado do Rio de Janeiro } \\
\text { e Embrapa agroindústria } \\
\text { de alimentos }\end{array}$} & \multirow{2}{*}{ 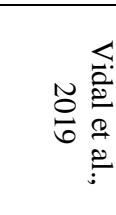 } \\
\hline & $\begin{array}{l}\text { Resíduos do } \\
\text { grão verde }\end{array}$ & Extrato & & & & & & \\
\hline
\end{tabular}




\begin{tabular}{|c|c|c|c|c|c|c|c|c|}
\hline $\begin{array}{l}\text { Caqui (Diospyros kaki } \\
\text { L.) }\end{array}$ & Fruto inteiro & Purê & $\begin{array}{l}\text { Glicerol e } \\
\text { Pectina }\end{array}$ & Casting & $\begin{array}{l}\text { Atividade } \\
\text { antimicrobiana }\end{array}$ & $\begin{array}{l}\text { O filme de caqui aplicado como tampa em } \\
\text { embalagens contendo cenoura, beterraba e } \\
\text { pepino minimamente processados apresentou } \\
\text { resultados semelhantes aos vegetais embalados } \\
\text { com filme de PVC nos parâmetros } \\
\text { microbiológicos e colorimétricos. O filme de } \\
\text { caqui retardou a perda de massa dos vegetais } \\
\text { ao longo do período de } 9 \text { dias de refrigeração, } \\
\text { mesmo que de forma menos eficaz em } \\
\text { comparação ao PVC. }\end{array}$ & $\begin{array}{l}\text { Universidade Federal do } \\
\text { Estado do Rio de Janeiro, } \\
\text { Universidade do Estado } \\
\text { do Rio de Janeiro e } \\
\text { Universidade Federal dos } \\
\text { Vales do Jequitinhonha e } \\
\text { Mucuri }\end{array}$ & 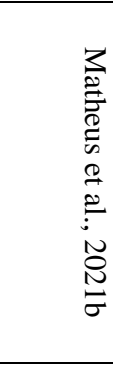 \\
\hline $\begin{array}{l}\text { Cenoura (Daucus } \\
\text { carota L.) }\end{array}$ & $\begin{array}{l}\text { Raspas e } \\
\text { pedaços não } \\
\text { uniformes }\end{array}$ & Pó & $\begin{array}{l}\text { Hidroxipropilm } \\
\text { etilcelulose e } \\
\text { fibras de } \\
\text { celulose }\end{array}$ & Casting & Não avaliada & Não avaliada & $\begin{array}{l}\text { Embrapa instrumentação, } \\
\text { Embrapa Agroindústria } \\
\text { tropical, Universidade } \\
\text { Federal de São Carlos e } \\
\text { Universidade do Estado } \\
\text { de São Paulo }\end{array}$ & 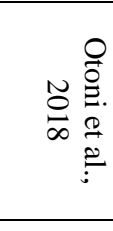 \\
\hline $\begin{array}{l}\text { Cenoura (Daucus } \\
\text { carota) }\end{array}$ & Resíduos & Pó & $\begin{array}{l}\text { Resíduo de } \\
\text { cápsula de } \\
\text { gelatina bovina }\end{array}$ & Casting & $\begin{array}{l}\text { Atividade } \\
\text { antioxidante }\end{array}$ & $\begin{array}{l}\text { Filmes adicionados de resíduos apresentaram } \\
\text { efeito protetor contra as reações primárias de } \\
\text { rancidez em óleo de girassol durante } \\
\text { armazenamento por } 28 \text { dias. }\end{array}$ & $\begin{array}{l}\text { Universidade Federal do } \\
\text { Rio Grande do Sul }\end{array}$ & 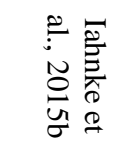 \\
\hline $\begin{array}{l}\text { Coco babaçu (Orbignya } \\
\text { phalerata Mart.) }\end{array}$ & Mesocarpo & $\begin{array}{l}\text { Pó de } \\
\text { mesocarpo }\end{array}$ & $\begin{array}{l}\text { Pectina cítrica, } \\
\text { cloreto de cálcio } \\
\text { dihidratado e } \\
\text { glicerol }\end{array}$ & Casting & Não avaliada & Não avaliada & $\begin{array}{l}\text { Universidade Federal do } \\
\text { Maranhão }\end{array}$ & 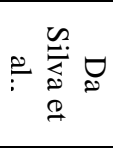 \\
\hline $\begin{array}{l}\text { Cupuaçu (Theobroma } \\
\text { grandiflorum) }\end{array}$ & Polpa & Purê & $\begin{array}{l}\text { Pectina e } \\
\text { nanopartículas } \\
\text { de quitosana }\end{array}$ & Casting & Não avaliada & Não avaliada & $\begin{array}{l}\text { Universidade Estadual } \\
\text { Paulista e Universidade } \\
\text { Estadual de Campinas } \\
\end{array}$ & 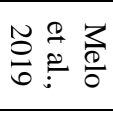 \\
\hline $\begin{array}{l}\text { Cúrcuma (Curcuma } \\
\text { longa L.) }\end{array}$ & Resíduo & Pó & Glicerol & Casting & $\begin{array}{l}\text { Atividade } \\
\text { antioxidante }\end{array}$ & Não avaliada & $\begin{array}{l}\text { Universidade de São } \\
\text { Paulo }\end{array}$ & 哭. 兽. 3 \\
\hline $\begin{array}{l}\text { Cúrcuma (Curcuma } \\
\text { longa L.) }\end{array}$ & $\begin{array}{l}\text { Resíduo } \\
\text { (extração do } \\
\text { amido) }\end{array}$ & Farinha & $\begin{array}{l}\text { Amido de } \\
\text { cúrcuma, } \\
\text { gelatina e } \\
\text { glicerol }\end{array}$ & Casting & $\begin{array}{l}\text { Atividade } \\
\text { antimicrobiana }\end{array}$ & $\begin{array}{l}\text { O revestimento adicionado de cúrcuma } \\
\text { retardou o crescimento microbiano em } \\
\text { salsichas refrigeradas por } 30 \text { dias. Estimou-se } \\
\text { que os revestimentos comestíveis } \\
\text { desenvolvidos prolongaram } \pm 10 \text { dias a vida } \\
\text { útil das salsichas refrigeradas. }\end{array}$ & $\begin{array}{l}\text { Universidade Federal de } \\
\text { Santa Catarina e } \\
\text { Universidade } \\
\text { Estadual de Campinas }\end{array}$ & 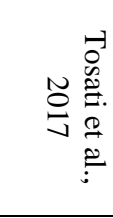 \\
\hline
\end{tabular}


Research, Society and Development, v. 10, n. 9, e49210918278, 2021

(CC BY 4.0) | ISSN 2525-3409 | DOI: http://dx.doi.org/10.33448/rsd-v10i9.18278

\begin{tabular}{|c|c|c|c|c|c|c|c|c|}
\hline $\begin{array}{l}\text { Feijão (Phaseolus } \\
\text { vulgaris), alfafa } \\
\text { (Medicago sativa), } \\
\text { amaranto (Amaranthus), } \\
\text { brócolis (Brassica } \\
\text { oleracea), rabanete } \\
\text { (Raphanus sativus) e } \\
\text { trevo (Trifolium) }\end{array}$ & $\begin{array}{l}\text { Resíduos de } \\
\text { brotos } \\
\text { (sementes não } \\
\text { germinadas, } \\
\text { folhas e brotos } \\
\text { avariados in } \\
\text { natura) }\end{array}$ & Farinha & $\begin{array}{l}\text { Amido de milho } \\
\text { e glicerol }\end{array}$ & Casting & Não avaliada & Não avaliada & $\begin{array}{l}\text { Universidade Federal de } \\
\text { Ciências da Saúde de } \\
\text { Porto Alegre }\end{array}$ & 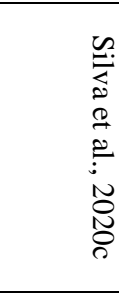 \\
\hline $\begin{array}{l}\text { Feijoa (Acca } \\
\text { sellowiana) }\end{array}$ & $\begin{array}{l}\text { Casca } \\
\text { (extração do } \\
\text { amido) }\end{array}$ & Farinha & $\begin{array}{l}\text { Amido de } \\
\text { pinhão, pectina } \\
\text { cítrica e glicerol }\end{array}$ & Casting & $\begin{array}{l}\text { Atividade } \\
\text { antioxidante e } \\
\text { antimicrobiana }\end{array}$ & $\begin{array}{l}\text { Filmes incorporados de casca de feijoa foram } \\
\text { capazes manter a qualidade e o peso constante } \\
\text { de maçãs ao longo de } 15 \text { dias de } \\
\text { armazenamento. }\end{array}$ & $\begin{array}{l}\text { Instituto Federal de Santa } \\
\text { Catarina, Universidade do } \\
\text { Planalto Catarinense e } \\
\text { Universidade Federal de } \\
\text { Santa Catarina }\end{array}$ & 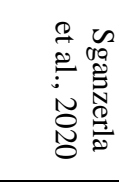 \\
\hline $\begin{array}{l}\text { Frutos de erva-mate } \\
\text { (Ilex paraguariensis A.) }\end{array}$ & Fruto inteiro & Extrato & $\begin{array}{l}\text { Amido de milho } \\
\text { e glicerol }\end{array}$ & Casting & $\begin{array}{l}\text { Atividade } \\
\text { antioxidante }\end{array}$ & Não avaliada & $\begin{array}{l}\text { Universidade Federal do } \\
\text { Paraná, Universidade } \\
\text { Federal de Santa Catarina } \\
\text { e University of Manitoba }\end{array}$ & 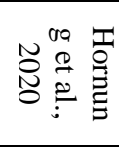 \\
\hline $\begin{array}{l}\text { Jabuticaba (Myrciaria } \\
\text { cauliflora (Mart.) O. } \\
\text { Berg) }\end{array}$ & $\begin{array}{l}\text { Resíduo } \\
\text { (bagaço) }\end{array}$ & Pó & \multirow{2}{*}{$\begin{array}{l}\text { Amido de milho } \\
\text { e glicerol }\end{array}$} & \multirow[t]{2}{*}{ Casting } & \multirow[t]{2}{*}{ Não avaliada } & \multirow[t]{2}{*}{ Não avaliada } & \multirow{2}{*}{$\begin{array}{l}\text { Universidade Federal do } \\
\text { Rio Grande do Sul }\end{array}$} & \multirow{2}{*}{ 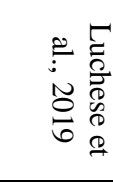 } \\
\hline $\begin{array}{l}\text { Mirtilo (Vaccinium } \\
\text { corymbosum L.) }\end{array}$ & $\begin{array}{l}\text { Resíduo } \\
\text { (bagaço) }\end{array}$ & Pó & & & & & & \\
\hline $\begin{array}{l}\text { Jabuticaba (Myrciaria } \\
\text { cauliflora) }\end{array}$ & Casca & Farinha & $\begin{array}{l}\text { Amido de milho } \\
\text { e glicerol }\end{array}$ & Casting & Não avaliada & Não avaliada & $\begin{array}{l}\text { Universidade Federal de } \\
\text { Mato Grosso, } \\
\text { Universidade Federal de } \\
\text { Pelotas e Instituto Federal } \\
\text { de Educação, Ciência e } \\
\text { Tecnologia de Mato } \\
\text { Grosso }\end{array}$ & 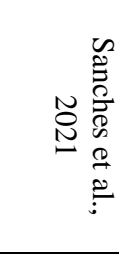 \\
\hline $\begin{array}{l}\text { Jabuticaba (Myrciaria } \\
\text { jaboticaba) }\end{array}$ & Casca & $\begin{array}{l}\text { Extrato } \\
\text { liofilizado }\end{array}$ & Carragena & Casting & $\begin{array}{l}\text { Atividade } \\
\text { antioxidante e } \\
\text { antimicrobiana }\end{array}$ & Não avaliada & $\begin{array}{l}\text { Universidade Federal do } \\
\text { Pampa, Universidade } \\
\text { Federal de Santa Maria, e } \\
\text { McGill University } \\
\end{array}$ & 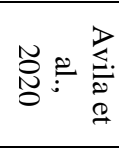 \\
\hline $\begin{array}{l}\text { Jaca (Artocarpus } \\
\text { heterophyllus) }\end{array}$ & $\begin{array}{l}\text { Semente } \\
\text { (extração do } \\
\text { amido) }\end{array}$ & \multirow[b]{2}{*}{ Extrato } & \multirow{2}{*}{$\begin{array}{l}\text { Amido de } \\
\text { semente de jaca, } \\
\text { antocianinas da } \\
\text { casca das uvas e } \\
\text { glicerol }\end{array}$} & \multirow[b]{2}{*}{ Casting } & \multirow[b]{2}{*}{ Não avaliada } & \multirow{2}{*}{$\begin{array}{l}\text { Houve mudança na coloração dos filmes } \\
\text { desenvolvidos ao serem utilizados como tampa } \\
\text { para amostras de peixe e camarão. Concluiu-se } \\
\text { a potencialidade de uso dos filmes inteligentes } \\
\text { como indicadores do processo de deterioração } \\
\text { do pescado. }\end{array}$} & \multirow{2}{*}{$\begin{array}{l}\text { Universidade Federal do } \\
\text { Ceará e Embrapa } \\
\text { Agroindústria Tropical }\end{array}$} & \multirow{2}{*}{ 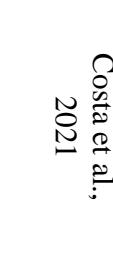 } \\
\hline $\begin{array}{l}\text { Uvas negras sem } \\
\text { semente (Midnight } \\
\text { beauty e Sables } \\
\text { seedless) }\end{array}$ & $\begin{array}{l}\text { Casca } \\
\text { (extração de } \\
\text { antocianina) }\end{array}$ & & & & & & & \\
\hline
\end{tabular}


Research, Society and Development, v. 10, n. 9, e49210918278, 2021

(CC BY 4.0) | ISSN 2525-3409 | DOI: http://dx.doi.org/10.33448/rsd-v10i9.18278

\section{Laranja (Citrus}

sinensis), maracujá

(Passiflora edulis),

melancia (Citrullus

lanatus), alface

(Lactuca sativa),

abobrinha (Cucurbita

pepo), cenoura (Daucus

carota), espinafre

(Spinacea oleracea),

hortelã (Mentha sp.)

taro (Colocasia

esculenta), pepino

(Cucumis sativus) $\mathrm{e}$

rúcula (Eruca sativa)
Soluções de

hidróxido de

amônio e

ácido

Vegetais

inteiros,

incluindo

(pH 7 e 9$)$ e

solução de

amônio e

amônio

ortofosfórico

(pH 9)

e caroço

Farinha
Soluções usadas

como extratores

Casting

Não avaliada
De modo geral, amostras de cenoura

minimamente processada revestidas por solução filmogênica desenvolvida

apresentaram menor perda de massa ao longo Universidade Federal do

de 12 dias em comparação com amostras

controle. Além disso, o crescimento

microbiano em cenouras revestidas foi similar

Estado do Rio de Janeiro

ao do controle utilizando filme de PVC.

\begin{tabular}{|c|c|c|c|c|c|}
\hline $\begin{array}{l}\text { Maçã (Malus } \\
\text { domestica) }\end{array}$ & $\begin{array}{l}\text { Bagaço } \\
\text { (casca, } \\
\text { sementes, } \\
\text { caules e } \\
\text { polpa) }\end{array}$ & Farinha & $\begin{array}{l}\text { Amido de } \\
\text { mandioca, } \\
\text { poli(butileno } \\
\text { adipato co- } \\
\text { tereftalato) e }\end{array}$ & Extrusão & $\begin{array}{l}\text { Atividade } \\
\text { antioxidante e } \\
\text { antimicrobiana }\end{array}$ \\
\hline
\end{tabular}

Universidade Federal de

Tecnologia do Paraná e

Universidade Estadual de

Londrina (Brasil),

Instituto Politécnico de

Castelo Branco,

Universidade de Lisboa e

Centro de Biotecnologia

de Plantas da Beira

Interior (Portugal) e

University College Dublin (Irlanda)

\begin{tabular}{|c|c|c|c|c|c|c|c|c|}
\hline $\begin{array}{l}\text { Malte (Hordeum } \\
\text { vulgare L.) }\end{array}$ & Bagaço & Farinha & $\begin{array}{l}\text { Pectina e } \\
\text { glicerol }\end{array}$ & Casting & Não avaliada & Não avaliada & $\begin{array}{l}\text { Universidade Federal de } \\
\text { Lavras e Embrapa } \\
\text { Instrumentação }\end{array}$ & 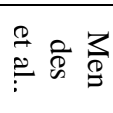 \\
\hline $\begin{array}{l}\text { Mamão (Carica papaya } \\
\text { L.) }\end{array}$ & Polpa & Purê & \multirow{2}{*}{$\begin{array}{l}\text { Pectina, ácido } \\
\text { cítrico e } \\
\text { ascórbico, } \\
\text { glicerol }\end{array}$} & \multirow{2}{*}{$\begin{array}{l}\text { Casting e } \\
\text { secagem em } \\
\text { forno de } \\
\text { convecção e } \\
\text { desidratador }\end{array}$} & \multirow{2}{*}{$\begin{array}{l}\text { Atividade } \\
\text { antioxidante }\end{array}$} & \multirow{2}{*}{$\begin{array}{l}\text { Filmes ativos e comestíveis aumentaram a vida } \\
\text { útil de pera minimamente processada. } \\
\text { Observou-se que a incorporação de ácido } \\
\text { ascórbico teve maior influência comparado ao } \\
\text { extrato de moringa na minimização da } \\
\text { alteração de cor das amostras ao longo de } 9 \\
\text { dias. }\end{array}$} & \multirow{2}{*}{$\begin{array}{l}\text { Embrapa Instrumentação } \\
\text { (Brasil) e Universidad del } \\
\text { Atlantico (Colômbia) }\end{array}$} & \multirow{2}{*}{ 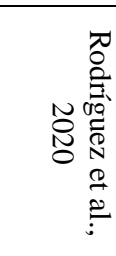 } \\
\hline $\begin{array}{l}\text { Moringa (Moringa } \\
\text { oleifera L.) }\end{array}$ & Folha & Pó & & & & & & \\
\hline $\begin{array}{l}\text { Manga (Mangifera } \\
\text { indica L.) }\end{array}$ & Polpa & Polpa & Pectina & Casting & Não avaliada & Não avaliada & $\begin{array}{l}\text { Universidade do Estado } \\
\text { de São Paulo, Embrapa } \\
\text { instrumentação, } \\
\text { Universidade Federal do } \\
\text { Paraná e Universidade } \\
\text { Federal de São Carlos }\end{array}$ & 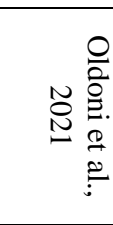 \\
\hline
\end{tabular}


Research, Society and Development, v. 10, n. 9, e49210918278, 2021

(CC BY 4.0) | ISSN 2525-3409 | DOI: http://dx.doi.org/10.33448/rsd-v10i9.18278

\begin{tabular}{|c|c|c|c|c|c|c|c|c|}
\hline $\begin{array}{l}\text { Mangaba (Hancornia } \\
\text { speciosa Gomes) }\end{array}$ & Polpa & Resíduo & $\begin{array}{l}\text { Quitosana, } \\
\text { extrato } \\
\text { etanólico e } \\
\text { lignina alcalina }\end{array}$ & Casting & $\begin{array}{l}\text { Atividade } \\
\text { antioxidante }\end{array}$ & Não avaliada & $\begin{array}{l}\text { Universidade Federal do } \\
\text { Rio Grande do Norte }\end{array}$ & 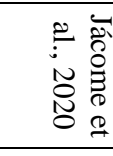 \\
\hline \multirow{2}{*}{$\begin{array}{l}\text { Maracujá (Passiflora } \\
\text { edulis Sims f. flavicarpa } \\
\text { degener) }\end{array}$} & Casca & Pó & \multirow{2}{*}{$\begin{array}{l}\text { Pectina e } \\
\text { glicerol }\end{array}$} & \multirow{2}{*}{ Casting } & \multirow{2}{*}{ Não avaliada } & \multirow{2}{*}{ Não avaliada } & \multirow{2}{*}{$\begin{array}{l}\text { Embrapa Instrumentação } \\
\text { e Universidade Federal de } \\
\text { São Carlos }\end{array}$} & \multirow{2}{*}{ 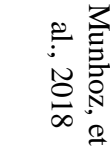 } \\
\hline & Polpa & Polpa & & & & & & \\
\hline $\begin{array}{l}\text { Mirtilo (Vaccinium } \\
\text { corymbosum L.) }\end{array}$ & $\begin{array}{l}\text { Resíduo } \\
\text { (bagaço) }\end{array}$ & Pó & $\begin{array}{l}\text { Amido de } \\
\text { mandioca e } \\
\text { glicerol }\end{array}$ & Casting & Não avaliada & $\begin{array}{l}\text { Os pigmentos presentes nos filmes } \\
\text { desenvolvidos à base de resíduo de mirtilo } \\
\text { foram capazes de migrar para amostras de } \\
\text { frango ao longo de } 10 \text { dias de armazenamento } \\
\text { refrigerado. }\end{array}$ & $\begin{array}{l}\text { Universidade Federal do } \\
\text { Rio Grande do Sul }\end{array}$ & 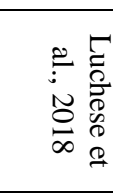 \\
\hline $\begin{array}{l}\text { Mirtilo (Vaccinium } \\
\text { corymbosum L.) }\end{array}$ & $\begin{array}{l}\text { Resíduo } \\
\text { (bagaço) }\end{array}$ & Pó & $\begin{array}{l}\text { Amido de } \\
\text { mandioca e } \\
\text { sorbitol }\end{array}$ & $\begin{array}{l}\text { Termocompre } \\
\text { ssão }\end{array}$ & Não avaliada & Não avaliada & $\begin{array}{l}\text { Universidade Federal do } \\
\text { Rio Grande do Sul }\end{array}$ & 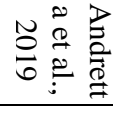 \\
\hline $\begin{array}{l}\text { Noz-pecã (Carya } \\
\text { illinoinensis) }\end{array}$ & Casca & \multirow[t]{2}{*}{ Farinha } & \multirow{2}{*}{$\begin{array}{l}\text { Amido de } \\
\text { mandioca }\end{array}$} & \multirow{2}{*}{$\begin{array}{l}\text { Termocompre } \\
\text { ssão }\end{array}$} & \multirow[t]{2}{*}{ Não avaliada } & \multirow[t]{2}{*}{ Não avaliada } & \multirow{2}{*}{$\begin{array}{l}\text { Universidade Federal do } \\
\text { Rio Grande do Sul }\end{array}$} & \multirow{2}{*}{ 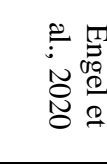 } \\
\hline $\begin{array}{l}\text { Pinhão (Araucaria } \\
\text { angustifólia) }\end{array}$ & Casca & & & & & & & \\
\hline $\begin{array}{l}\text { Repolho roxo (Brassica } \\
\text { oleraceae L.) }\end{array}$ & $\begin{array}{l}\text { Folhas } \\
\text { (extração de } \\
\text { antocianina) }\end{array}$ & Extrato & $\begin{array}{l}\text { Acetato de } \\
\text { celulose, } \\
\text { glicerol e } \\
\text { extrato de } \\
\text { antocianina } \\
\end{array}$ & Casting & Não avaliada & Não avaliada & $\begin{array}{l}\text { Universidade Federal de } \\
\text { Viçosa }\end{array}$ & 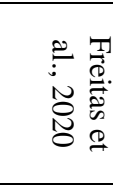 \\
\hline $\begin{array}{l}\text { Tamarindo (Tamarindus } \\
\text { indica) }\end{array}$ & $\begin{array}{l}\text { Semente } \\
\text { (extração de } \\
\text { xiloglucano) }\end{array}$ & Extrato & $\begin{array}{l}\text { Xiloglucano e } \\
\text { glicerol }\end{array}$ & Casting & Não avaliada & $\begin{array}{l}\text { Amostras de mamão embaladas com filme à } \\
\text { base de xiloglucano de resíduos de sementes de } \\
\text { tamarindo apresentaram produção de etileno e } \\
\text { dióxido de carbono estatisticamente similar as } \\
\text { amostras embaladas com PVC. No entanto, o } \\
\text { filme otimizado não foi capaz de retardar a } \\
\text { perda de massa do mamão ao longo de } 8 \text { dias } \\
\text { de armazenamento de forma tão eficaz quanto } \\
\text { o PVC. }\end{array}$ & $\begin{array}{l}\text { Instituto Federal do } \\
\text { Ceará, Embrapa } \\
\text { Agroindústria Tropical, } \\
\text { Universidade Federal do } \\
\text { Ceará, Universidade } \\
\text { Estadual do Ceará }\end{array}$ & 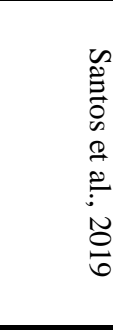 \\
\hline
\end{tabular}

Fonte: Autores. 
Atualmente, há grande interesse na valorização e aproveitamento de resíduos agroindustriais para a formulação de filmes, devido à relativa abundância, baixo custo, não toxicidade, biodegradabilidade e biocompatibilidade (Omran et al., 2021; Chang et al., 2021; Ranganathan et al., 2020). No entanto, ainda é um desafio produzir filmes à base de resíduos vegetais com propriedades mecânicas e de barreira mais competitivas que os plásticos convencionais. Por exemplo, Nogueira et al. (2019) observaram que maiores quantidades de polpa de amora adicionada em soluções filmogênicas à base de amido de araruta resultaram em filmes menos resistentes e mais permeáveis ao vapor de água. Esse resultado é comumente observado em outros estudos e frequentemente associado à presença de carboidratos simples e outros componentes hidrofílicos presentes nos resíduos (Silva et al., 2020b; Melo et al., 2019b; Jirukkakul, 2016). Nesse sentido, o uso de nanopartículas como agentes de reforço em filmes vem sendo explorado e apresenta grande potencial na área de biopolímeros (Acquavia et al., 2020; Ates et al., 2020; Souza et al., 2020b; Azeredo et al., 2017), contribuindo também para o aproveitamento dos resíduos agroindustriais, uma vez que nanopartículas obtidas de celulose, por exemplo, destacam-se por proporcionarem bom desempenho mecânico e de barreira aos filmes nanocompósitos (Omran et al., 2021; Pakutsah \& Aht-Ong, 2020; Mishra et al., 2018).

\section{Filmes Nanocompósitos à Base de Resíduos Agroindustriais}

Compósitos são caracterizados por apresentar a combinação de dois ou mais materiais com estrutura química e geométrica distintas, onde um deles é o responsável pela formação da matriz (fase contínua) e o outro pelo reforço (fase dispersa). Quando se trata de um nanocompósito, o agente de reforço aplicado possui uma dimensão em escala nanométrica, isto é, entre 1 a $100 \mathrm{~nm}$, o que fornece interessantes características ao material dada a alta relação superfície-volume dos nanocompósitos e a elevada interação entre a matriz e o reforço (Ates et al., 2020). O uso de fontes renováveis como base para a elaboração dos nanocompósitos é de grande importância e tem sido investigado em inúmeras áreas, como engenharia, biomedicina e materiais (Ates et al., 2020; Souza et al. 2020), sendo a celulose um dos polímeros de destaque para a área de filmes nanocompósitos aplicados como embalagem (Wróblewska-Krepsztul et al., 2018).

A produção de nanopartículas a partir de resíduos agroindustriais é crescente (Omran et al., 2021). Huang et al. (2020) produziram filmes à base de amido de mandioca reforçados com nanofibrilas de celulose modificadas (por tratamento com ácido málico e o agente de acoplamento de silano KH-550). As nanopartículas foram produzidas a partir de resíduos de mandioca (não especificado). Os filmes apresentaram característica hidrofóbica e boas propriedades mecânicas e de barreira (Huang et al., 2020).

Coelho et al. (2020) desenvolveram um filme à base de amido reforçado com nanocristais de celulose do bagaço de uva. À medida que maiores concentrações de nanopartículas compuseram as formulações, os filmes apresentaram maior resistência mecânica e menor maleabilidade. Em relação às propriedades de barreira, observou-se que as menores concentrações de nanocristais resultaram em menores valores de permeabilidade ao vapor de água comparado aos filmes controle e àqueles adicionados de maiores concentrações de nanocristais. Sugeriu-se que a concentração de nanopartículas inserida na formulação deve ser suficiente para se dispersar na matriz, sem gerar aglomeração, e assim, proporcionar um aumento da tortuosidade na estrutura dos filmes de modo que dificulte a permeação das moléculas de água (Coelho et al., 2020). Outro estudo evidenciou resultado semelhante em filmes à base de amido de batata reforçados com nanofibras de celulose de coroa de abacaxi. As nanofibras foram efetivas para reforçar os filmes, porém maiores concentrações estiveram associadas a redução da propriedade de barreira dado a presença de nanofibras aglomeradas (Balakrishnan et al., 2017).

Pelissari et al. (2017) desenvolveram nanocompósitos à base de amido de banana incorporados de nanofibras de celulose de casca de banana e avaliaram a influência destas na matriz polimérica, bem como o efeito do tratamento mecânico (homogeneizador de alta pressão) sobre as nanofibras. Conforme o tratamento mecânico das nanofibras foi intensificado, os nanocompósitos apresentaram maior tensão na ruptura, módulo de elasticidade, opacidade, cristalinidade e menor solubilidade 
em água. No entanto, o tratamento mais drástico gerou danos nas fibras, o que impactou negativamente as propriedades gerais dos nanocompósitos (Pelissari et al., 2017).

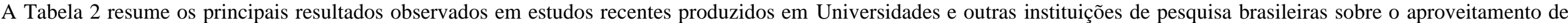
resíduos agroindustriais para a produção de filmes nanocompósitos.

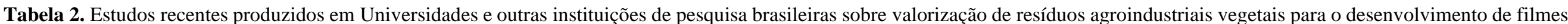
nanocompósitos.

\begin{tabular}{|c|c|c|c|c|c|c|c|}
\hline Resíduo & $\begin{array}{l}\text { Tipo de } \\
\text { nanopartícula } \\
\text { produzida }\end{array}$ & $\begin{array}{l}\text { Método de pré- } \\
\text { tratamento }\end{array}$ & $\begin{array}{l}\text { Caracterização das } \\
\text { nanopartículas }\end{array}$ & $\begin{array}{l}\text { Composição do } \\
\text { filme } \\
\text { nanocompósito }\end{array}$ & $\begin{array}{l}\text { Caracterização do } \\
\text { filme nanocompósito }\end{array}$ & Principais propriedades do filme nanocompósito & Ref. \\
\hline $\begin{array}{l}\text { Bainhas externas e } \\
\text { medianas de } \\
\text { pupunha }\end{array}$ & $\begin{array}{l}\text { Nanofibrilas de } \\
\text { celulose (NFBC) }\end{array}$ & $\begin{array}{l}\text { Desfibrilação } \\
\text { mecânica }\end{array}$ & Não avaliada & $\begin{array}{l}\text { Quitosana e } \\
\text { NFBC }\end{array}$ & $\begin{array}{l}\text { TR: } 47,45-56,59 \mathrm{MPa} \\
\text { ER: } 1,67-5,43 \% \\
\text { ME: } 1931,87-5384,05 \\
\text { MPa } \\
\text { Transp.: } 43,32-49,16 \%\end{array}$ & $\begin{array}{l}\text { - A adição das NFBC resultaram em filmes mais resistentes (filme nanocompósito } \\
\text { com } 1,5 \% \text { de NFBC aumentou } 1300 \% \text { o módulo elástico e } 280 \% \text { tensão na } \\
\text { ruptura). No entanto, menores valores de AR foram observados para os filmes } \\
\text { nanocompósitos, indicando que a flexibilidade foi afetada negativamente pela } \\
\text { incorporação das NFBC, } \\
\text { - Esses resultados podem ser atribuídos devido à característica de elevada RA das } \\
\text { nanopartículas que contribuem para a formação de uma forte interação NFBC- } \\
\text { quitosana, que restringe a mobilidade da rede polimérica, tornando-a rígida e pouco } \\
\text { flexível, } \\
\text { - Ademais, a adição de NFBC reduziu a transmissão de luz dos filmes } \\
\text { nanocompósitos, sugerindo que a forte interação NFBC-quitosana também elevou a } \\
\text { cristalinidade dos filmes e, consequentemente, sua turbidez. }\end{array}$ & 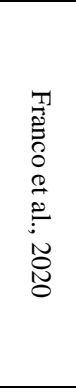 \\
\hline $\begin{array}{l}\text { Bainhas externas } \\
\text { de pupunha }\end{array}$ & $\begin{array}{l}\text { Nanofibrilas de } \\
\text { celulose (NFBC) }\end{array}$ & $\begin{array}{l}\text { Desfibrilação } \\
\text { mecânica }\end{array}$ & $\begin{array}{l}\text { Diâm.: } 10-30 \mathrm{~nm} \\
\text { Morf.: fibras longas e } \\
\text { emaranhadas }\end{array}$ & $\begin{array}{l}\text { Amido de } \\
\text { mandioca, } \\
\text { glicerol e NFBC }\end{array}$ & $\begin{array}{l}\text { Esp.: } 0,121-0,123 \mathrm{~mm} \\
\text { TR: } 6,417-13,704 \mathrm{MPa} \\
\text { ER: } 4,950-45,597 \% \\
\text { SA: } 16,43-19,85 \% \\
\text { PVA: } 1,14-1,27\left(\mathrm{~g} \mathrm{~m}^{-1}\right. \\
\left.\mathrm{s}^{-1} \mathrm{~Pa}^{-1}\right) \times 10^{-10} \\
\text { Transp.: } 35,01-42,93 \%\end{array}$ & $\begin{array}{l}\text { - As NFBC foram capazes de reforçar os filmes à base de amido, aumentando a } \\
\text { tensão na ruptura em até } 306 \% \text { em relação ao filme controle (sem NFBC), } \\
\text { - Observou-se maior propriedade de barreira nos filmes nanocompósitos, com a } \\
\text { redução da PVA, } \\
\text { - Quanto maior a adição de NFBC maior opacidade os filmes nanocompósitos } \\
\text { apresentaram, } \\
\text { - Não houve variação relevante nos perfis térmicos dos filmes com ou sem NFBC. }\end{array}$ & 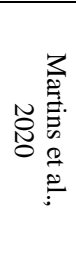 \\
\hline Bagaço de uva & $\begin{array}{l}\text { Nanocristais de } \\
\text { celulose (NCC) }\end{array}$ & Hidrólise ácida & Morf.: agulha & $\begin{array}{l}\text { Amido de } \\
\text { batata, glicerol e } \\
\text { NCC }\end{array}$ & $\begin{array}{l}\text { Esp.: } 0,08-0,11 \mathrm{~mm} \\
\text { TR: } 13,03-36,64 \mathrm{MPa} \\
\text { ER: } 3,66-10,29 \% \\
\text { ME: } 20,96 \mathrm{MPa} \text { (maior } \\
\text { valor alcançado) } \\
\text { PVA: } 4,25-6,63 \mathrm{~g} \mathrm{~h}^{-1} \\
\mathrm{~m}^{-1} \mathrm{~Pa}^{-1} \\
\text { Op.: } 4,27-6,35 \%\end{array}$ & $\begin{array}{l}\text { - A incorporação de NCC nos filmes aumentaram a tensão na ruptura e o módulo } \\
\text { de elasticidade, podendo ser explicado pela forte interação das ligações de } \\
\text { hidrogênio entre o CNC e as moléculas de amido, } \\
\text { - Enquanto a adição de pequenas concentraçães de NCC diminuíram os valores de } \\
\text { elongação na ruptura comparado ao controle, indicando que o CNC restringe a } \\
\text { movimentação da matriz do amido, } \\
\text { - A presença de NCC não alterou significativamente a solubilidade em água dos } \\
\text { filmes quando comparado ao controle, } \\
\text { - A PVA diminuiu com a adição de NCC comparado ao filme controle devido ao } \\
\text { aumento da tortuosidade das moléculas de água na matriz polimérica, } \\
\text { - A incorporação de concentrações acima de } 5 \% \text { de CNC nos filmes aumentou os } \\
\text { valores de opacidade. }\end{array}$ & 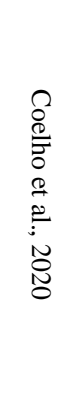 \\
\hline
\end{tabular}


$\begin{array}{lll}\text { Casca de banana } & \begin{array}{l}\text { Nanofibras de } \\ \text { celulose (NFC) }\end{array} & \begin{array}{l}\text { Hidrólise ácida e } \\ \text { enzimática }\end{array} \quad-\end{array}$

\begin{tabular}{ll}
\hline Resíduos de caju & $\begin{array}{l}\text { Nanocristais de } \\
\text { celulose (NCC) }\end{array}$ \\
\hline $\begin{array}{l}\text { Semente de } \\
\text { manga (amido } \\
\text { extraído do } \\
\text { núcleo) }\end{array}$ & $\begin{array}{l}\text { Nanocristais de } \\
\text { amido (NCA) }\end{array}$ \\
\hline
\end{tabular}

Hidrólise ácida

Semente de

manga (celulose Nanocristais de

celulose (NCC)

\section{Sabugo de milho}

(SM)

\section{Casca de milho}

(CM)

Farelo de trigo
(FT)

Casca de coco

(CC)

Hidrólise ácida

Nanocristais de

Hidrólise ácida
Esp.: 0,076-0,078 mm

TR: $12,3-96,6 \mathrm{MPa}$

ER: $30,6-50 \%$

Amido de
banana, glicerol

e NFC $\quad$ PVA: 6,4-8,6 ( $\mathrm{g} \mathrm{m} \mathrm{s}$

Pa) $\times 10^{-11}$

Op.: $64,37-70,53 \%$

TR: $48,49-71,95 \mathrm{MPa}$

Diâm.: 17,5 nm

Compr.: $276 \mathrm{~nm}$

Morf.: agulha

PZ: $-26,1 \mathrm{mV}$

Rend.: $5,6 \%$

Celulose ER: $3,06-5,21 \%$

bacteriana, ME: $1,74-2,37 \mathrm{GP}$

SA: $84.06-92,4 \%$

PVA: $1,89-2,73$ (g mm $\left.\mathrm{kPa}^{-1} \mathrm{~h}^{-1} \mathrm{~m}^{-2}\right)$

As embalagens produzidas com NFC foram capazes de proteger o alimento

embalado contra oxidação lipídica durante todo período de armazenamento,

- A presença de NFC na matriz de amido manteve a textura inicial das castanhas de

caju durante $\mathrm{o}$ armazenamento,

- As NFC melhoraram a resistencia à penetração da água do filme de amido devido ao aumento da tortuosidade da matriz.

- A adição de NCC aumentou a tensão na ruptura e o módulo de elasticidade do

filme nanocompósito, enquanto seu efeito na elongação na ruptura não foi

significativo. Isto se deve pela forte adesão e pela formação de uma rede de

percolação na interface NCC-matriz,

TR: $13,47-25,66 \mathrm{MP}$

de áminuição da permeabilidade ao vapor de água quando

acrescentado o NCC, atribuído à sua insolubilidade na água e alta cristalinidade.

$\begin{array}{ll}\text { Tamanho de partícula: } & \text { TR: } 13,47-25,66 \mathrm{MPa} \\ \text { (condição otimizada: }\end{array}$

$67,1 \mathrm{~nm}$

Morf.: arredondada

PZ: $-24 \mathrm{mV}$

Crist.: $62,6 \%$

(condição ot

ER: $2,53-15,31 \%$

(condição otimizada:

$10,35 \%$ )

Amido de

Diâm.: $18 \mathrm{~nm}$

Compr.: $270 \mathrm{~nm}$

semente de

ME: 1181 - 1967 MP

manga, glicerol (condição otimizada:

$1299 \mathrm{MPa})$

PVA: $1,133-1,483 \mathrm{~g}$

$\mathrm{mm} \mathrm{m}^{-2} \mathrm{~h}^{-1} \mathrm{kPa}^{-1}$

RA: 15

RA: 15

Crist.: $80,3 \%$

(condição otimizad

$1,265 \mathrm{~g} \mathrm{~mm} \mathrm{~h}^{-1} \mathrm{kPa}^{-1} \mathrm{~m}^{-}$

Compr.: $302 \mathrm{~nm}$

Larg.: 8,12 nm

RA: 32,19

Morf.: agulha

Rend.: $38,7 \%$

Compr.: $298,3 \mathrm{~nm}$
Larg. $7,30 \mathrm{~nm}$

Larg.: $7,30 \mathrm{n}$
RA: 40,86

Morf.: agulha

Rend.: $25,4 \%$

Compr.: -

Larg.: -

RA: -

Esp.: 0,019 mm

ER: $195,2 \%$

ER: $195,2 \%$

Aa: 0,611

Esp.: $0,027 \mathrm{~mm}$

TR: 6,99 MPa

ER: $155,2 \%$

Quitosana, Aa: 0,658

$\begin{array}{ll}\text { SM, CM, FT e } & \text { Esp.: 0,027 mm } \\ \text { TR: 4,03 MPa }\end{array}$

Morf.: agulha

Rend.: $28 \%$

Compr.: $254 \mathrm{~nm}$

Larg.: 6,32 n

RA: 40,18

Morf.: agulha
Rend.: $12,5 \%$
ER: $141,0 \%$

Aa: 0,601

U: $20,86 \%$

Esp.: $0,040 \mathrm{~mm}$

TR: $11,38 \mathrm{MPa}$

Aa: $15,13 \%$
- NCC foi mais eficaz do que o NCA em melhorar as propriedades de tensão na ruptura e barreira ao vapor de água dos filmes,

NCA apresentou menor efeito sobre a redução da elongação na ruptura dos filmes

- A adição de nanopartículas, sob condições otimizadas, resultou em um filme com maior resistência e propriedade de barreira ao vapor de água, porém menor

elongação na ruptura em comparação com filme sem as nanopartículas.

-

- A adição dos NCC diminuiu a espessura dos filmes comparado ao controle, mantendo as propriedades de barreira inalteradas,

Os filmes com NCC advindas de CC e SM apresentaram melhores valores de tensão na ruptura comparado ao controle,

- A incorporação dos NCC aumentou a flexibilidade dos filmes,

- A utilização de NCC de CM apresentou maior atividade de água comparado aos demais

Os filmes com NCC de SM e CC apresentaram menor teor de umidade em comparação com os filmes com NCC de FT e CM.

(1)




\begin{tabular}{|c|c|c|c|c|c|c|c|}
\hline $\begin{array}{l}\text { Bagaço de } \\
\text { mandioca }\end{array}$ & $\begin{array}{l}\text { Nanofibras de } \\
\text { lignocelulose } \\
\text { (NFLC) }\end{array}$ & $\begin{array}{l}\text { Hidrólise } \\
\text { enzimática }\end{array}$ & $\begin{array}{l}\text { Diâm.: } 4,5 \mathrm{~nm} \\
\text { RA: > } 85 \\
\text { PZ: - } 6,47 \mathrm{mV} \\
\text { Crist.: } 31,4 \%\end{array}$ & $\begin{array}{l}\text { Amido de } \\
\text { mandioca, } \\
\text { NFLC e glicerol }\end{array}$ & $\begin{array}{l}\text { Esp.: } 0,12 \mathrm{~mm} \\
\text { TR: } 5,3-6,6 \mathrm{MPa} \\
\text { ER: } 44,4-48,7 \% \\
\text { Dens.: } 1,36-1,47 \mathrm{~g} \mathrm{~cm} \\
\text { SA: } 22,56-23,83 \% \\
\text { PVA: } 0,032-0,047 \mathrm{~g} \\
\text { mm m-2 } \mathrm{h}^{-1} \mathrm{kPa}^{-1} \\
\text { Op.: } 0,77-1,28 \mathrm{~A}_{600} \\
\mathrm{~mm}^{-1}\end{array}$ & $\begin{array}{l}\text { - A presença de NFLC diminuiu a solubilidade dos filmes comparado ao controle, } \\
\text { - A NFLC reduziu a PVA dos filmes, que está associada a uma diminuição do } \\
\text { coeficiente de difusão imposto pela presença das nanopartículas, } \\
\text { - A adiçãa de NFLC aumentou em } 37,5 \% \text { a tensão na ruptura dos filmes em } \\
\text { comparação com a amostra controle, indicando boa interação molecular entre o } \\
\text { amido de mandioca e a NFLC, } \\
\text { - A incorporação da NFLC resultou em uma menor flexibilidade dos filmes. }\end{array}$ & 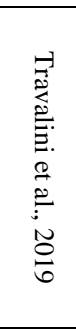 \\
\hline \multirow{2}{*}{ Palha de soja } & $\begin{array}{l}\text { Nanofibras de } \\
\text { celulose (NFC) }\end{array}$ & \multirow{2}{*}{$\begin{array}{l}\text { Hidrólise química } \\
\text { e enzimática }\end{array}$} & $\begin{array}{l}\text { Compr.: não uniformes } \\
\text { (aglomeração) } \\
\text { Diâm.: } 9,4 \mathrm{~nm} \\
\text { Rend.: } 13,3 \% \\
\text { PZ: }-24,5 \mathrm{mV}\end{array}$ & \multirow{2}{*}{$\begin{array}{l}\text { Isolado de } \\
\text { proteína de soja, } \\
\text { glicerol, NFC e } \\
\text { NCC }\end{array}$} & $\begin{array}{l}\text { Esp.: } 0,080 \mathrm{~mm} \\
\text { TR: } 9 \mathrm{MPa} \\
\text { ER: } 8 \% \\
\text { ME: } 575 \mathrm{MPa} \\
\text { SA: } 33 \% \\
\text { U: } 17 \% \\
\text { PVA: } 7 \times 10^{-10} \mathrm{~g} \mathrm{~m}^{-1} \mathrm{~s}^{-1} \\
\text { Pa }^{-1}\end{array}$ & \multirow{2}{*}{$\begin{array}{l}\text { - A incorporação de NFC e NCC aumentou a tensão na ruptura e o módulo de } \\
\text { elasticidade dos filmes de isolado de proteína de soja, em comparação com o } \\
\text { controle, } \\
\text { - NFC e NCC diminuíram a elongação na ruptura do filme em } 8 \% \text { e } 5 \% \text {, } \\
\text { respectivamente, } \\
\text { - A incorporação de NCC diminui a solubilidade em água do filme de } 26 \% \text { para } \\
20 \% \text {, enquanto a adição de NFC aumenta a solubilidade em água de } 26 \% \text { para } 33 \% \\
\text { em comparação com o controle, } \\
\text { - A presença de NFC na matriz provocou a diminuição da permeabilidade ao vapor } \\
\text { de água dos filmes, que está atribuído à menor razão de aspecto e a presença de } \\
\text { açúcares redutores. }\end{array}$} & \multirow{2}{*}{ 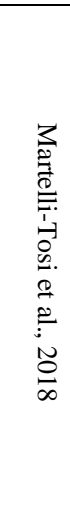 } \\
\hline & $\begin{array}{l}\text { Nanocristais de } \\
\text { celulose (NCC) }\end{array}$ & & $\begin{array}{l}\text { Compr.: } 100-600 \mathrm{~nm} \\
\text { Diâm.: } 9,4 \mathrm{~nm} \\
\text { Rend.: } 12,4 \% \text { PZ: - } \\
28,8 \mathrm{mV}\end{array}$ & & $\begin{array}{l}\text { Esp.: } 0,082 \mathrm{~mm} \\
\text { TR: } 8,4 \mathrm{MPa} \\
\text { ER: } 4,2 \% \\
\text { ME: } 537 \mathrm{MPa} \\
\text { SA: } 20 \% \\
\text { U: } 17 \% \\
\text { PVA: } 14 \times 10^{-10} \mathrm{~g} \mathrm{~m}^{-1} \mathrm{~s}^{-1} \\
\text { Pa }^{-1}\end{array}$ & & \\
\hline Palhas de soja & $\begin{array}{l}\text { Nanofibras de } \\
\text { celulose (NFC) }\end{array}$ & $\begin{array}{l}\text { Moagem } \\
\text { mecânica e } \\
\text { hidrólise } \\
\text { enzimática }\end{array}$ & $\begin{array}{l}\text { Diâm.: } 40-120 \mathrm{~nm} \\
\text { Compr.: não uniforme } \\
\text { e variável }\end{array}$ & $\begin{array}{l}\text { Purê de mamão, } \\
\text { glicerol e NFC }\end{array}$ & $\begin{array}{l}\text { Esp.: } 0,071-0,086 \mathrm{~mm} \\
\text { TR: } 6,42-7,30 \mathrm{MPa} \\
\text { ER: } 7,09-9,33 \% \\
\text { PVA: } 1,38-3,50 \mathrm{gmm} \\
\mathrm{m}^{-2} \mathrm{~h}^{-1} \mathrm{kPa}^{-1}\end{array}$ & $\begin{array}{l}\text { - A NFC apresentou melhorias nas propriedades mecânicas e de barreira ao vapor } \\
\text { de água, } \\
\text { - A NFC teve maior influência no estresse (tensão na ruptura) do que na } \\
\text { deformação, apesar da presença de grupos hidroxila e carboxila que aumentam a } \\
\text { afinidade por água e moléculas polares adicionando um efeito plastificante na } \\
\text { matriz, } \\
\text { - A NFC foi mais eficaz na diminuição da permeabilidade ao vapor de água mesmo } \\
\text { para filmes mais finos, provavelmente devido maior tortuosidade dos filmes } \\
\text { induzido principalmente pela elevada razão de aspecto das fibras, } \\
\text { - Não houve diferença relevante no comportamento térmico dos filmes adicionados } \\
\text { ou não de NFC. }\end{array}$ & 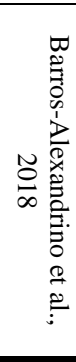 \\
\hline
\end{tabular}

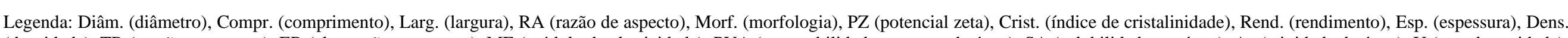

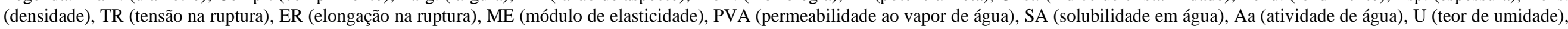
Transp. (transparência), Op. (opacidade)

Fonte: Autores.. 
Os materiais celulósicos têm se demonstrado ótimas fontes para produção de nanopartículas, pois além de abundantes na natureza, são ambientalmente amigáveis e não muito custosos (Mishra et al., 2018). A celulose é um homopolissacarídeo linear formado por moléculas de $\beta$-D-glicopiranose unidas por ligações glicosídicas $\beta$-(1-4). As microfibrilas são os principais componentes da celulose e são compostos por regiões cristalinas (ordenadas) alternadas com regiões amorfas (desordenadas) constituídas de hemicelulose, lignina e pectina (Balakrishnan et al. 2017; Coelho et al., 2020). Partículas de celulose com pelo menos uma dimensão em nanoescala são denominadas de nanoceluloses, que, por sua vez, podem ser classificadas em nanocristais de celulose (nanopartículas retas obtidas principalmente de regiões altamente cristalinas) ou em nanofibras de celulose (nanopartículas longas e flexíveis formada por agregações de fibrilas elementares compostas de partes cristalinas e amorfas) (Souza et al., 2020b; Mishra et al., 2018; Azeredo et al., 2016). Há diversos tratamentos mecânicos, químicos e biológicos para isolamento e produção de nanoceluloses a partir de materiais lignocelulósicos, como por exemplo moagem, extrusão, hidrólise enzimática, hidrólise química, carboxilação e sulfonação (Souza et al., 2020b). Comumente, a obtenção de nanocelulose a partir de resíduos agroindústrias é realizada via hidrólise ácida (Mishra et al., 2018). Em um estudo usando casca de mandioca, os autores observaram que o tratamento alcalino seguido de branqueamento foi adequado para a extração de celulose, e tanto o tratamento mecânico (homogeneização e ultrassom) quanto o químico (hidrólise com ácido sulfúrico) favoreceram a produção de nanoceluloses com propriedades químicas semelhantes. Observou-se que o tratamento químico gerou nanofibras com maior cristalinidade $(63,3 \%)$ do que o tratamento mecânico $(62,1 \%)$, indicando que o ácido sulfúrico foi capaz de degradar mais a região amorfa da celulose (Widiarto et al., 2019).

O uso de nanocelulose ao invés de fibras de celulose em filmes apresenta a vantagem de formação de poros mais complexos e menores nos filmes, devido à maior área de superfície, maior tensão na ruptura, rigidez e flexibilidade, boa propriedade térmica e alta razão de aspecto das nanopartículas, o que pode contribuir para uma densidade maior dentro do filme e menor permeabilidade (Souza et al., 2020b; Mishra et al., 2018; Pelissari et al., 2017). Wang et al. (2017) investigaram a influência da adição de fibras de celulose e de nanocristais de celulose isolados da polpa de amora em filmes à base de alginato de sódio. Observou-se que as fibras geraram filmes com maior espessura, menor resistência mecânica e flexibilidade e maiores valores de permeabilidade ao vapor de água comparado aos filmes controle e adicionado de nanopartículas. Em contrapartida, as nanopartículas tiveram efeito positivo nas propriedades mecânica e de barreira dos filmes. Esses resultados sugerem que as dimensões em nanoescala dos cristais de celulose obtidos foram capazes de prover maior reforço na matriz polimérica do que as fibras de celulose em escala milimétrica, provavelmente devido à forte interação entre as nanopartículas e o alginato (Wang et al., 2017).

Assim, as nanoceluloses isoladas de resíduos são promissores agentes de reforço em filmes, melhorando suas propriedades mecânicas e de barreira, sem necessariamente comprometer sua biodegradabilidade intrínseca. Além disso, essa estratégia contribui para a valorização de resíduos agroindustriais altamente produzidos e descartados. Por fim, outro aspecto a ser enfatizado, é a potencial bioatividade advinda desses resíduos que, ao serem incorporados em formulações de filmes, favorecem a aplicação como embalagem ativa para alimentos.

\section{Filmes à Base de Resíduos Agroindustriais: uma Alternativa de Embalagem ativa e Biodegradável}

Tradicionalmente, os materiais usados para embalagem de alimentos devem conter, preservar e proteger os alimentos e ainda permitir a rotulagem e informação sobre produto/ marca (Sharmila et al., 2020). As embalagens constituem-se importantes barreiras físicas reduzindo risco de exposição do alimento ao ambiente circundante e, consequentemente, sua contaminação com corpos estranhos e/ou micro-organismos, o que contribui para prolongar a vida útil dos produtos alimentícios e reduzir perdas de alimentos (Chisenga et al., 2020). Atualmente, é notório o crescente interesse em pesquisa e desenvolvimento de embalagens ativas e inteligentes que, diferentemente das tradicionais, apresentam uma interação intencional e desejável com o alimento 
embalado ou com o ambiente interno da embalagem de forma a aumentar a preservação e proteção do produto (embalagem ativa) ou ainda, monitorar as condições de qualidade do produto (embalagem inteligente) (Almasi et al. 2020). Assim, comumente, os resíduos agroindustriais vegetais, como cascas, sementes, talos e bagaços, constituem-se como fontes de compostos bioativos que podem ser incorporados na matriz polimérica de filmes para atuarem como agentes antimicrobianos, antioxidantes, aromáticos e/ou indicativos (de monitoramento de segurança e qualidade) (Bhargava et al., 2020).

Diversos estudos avaliaram o uso de resíduos agroindustriais para o desenvolvimento de filmes ativos e inteligentes. Rodsamran \& Sothornvit (2019a) observaram que o extrato de resíduo de casca de limão foi capaz de propiciar elevada atividade antioxidante nos filmes à base de pectina (532,04 a 597,98 $\mu \mathrm{M}$ Trolox/g filme pela análise de ABTS, 38,70 a 51,98 $\mu \mathrm{M}$ Trolox/ g filme pela análise de DPPH), atribuída principalmente pelo teor de fenólicos totais presentes (75,15 a 81,01 mg GAE/g film). Além disso, filmes com adição de extrato do resíduo contribuíram para retardar a oxidação do óleo de soja durante 30 dias de armazenamento, sugerindo potencial uso como embalagem ativa. Soofi et al. (2021) também aproveitaram resíduos de limão em pó para incrementar a bioatividade em filmes nanocompósitos. A adição deste resíduo foi associada a uma importante propriedade antimicrobiana contra os cinco patógenos de origem alimentar testados, sendo que o óleo essencial de Satureja khuzistanica L. também adicionado nos filmes atuou de maneira sinérgica nesse efeito antimicrobiano.

Guo et al. (2021) desenvolveram filmes inteligentes à base de pectina de casca de melancia usando extrato de beterraba como indicador colorimétrico sensível ao $\mathrm{pH}$. Além de melhorias nas propriedades térmicas e de barreira ao oxigênio, ao vapor de água e à luz e maior rigidez nos filmes incorporados de extrato de beterraba (em especial, no filme com $2 \%$ de extrato), observou-se também boa estabilidade de cor em condições naturais, bem como presença de resposta colorimétrica frente a uma ampla faixa de valores de $\mathrm{pH}$, variando de 3 a 10. Ademais, o filme com adição de $2 \%$ de extrato de beterraba provou potencial aplicação como embalagem inteligente para monitoramento de qualidade de carne bovina resfriada, uma vez que houve mudança de coloração do dia 0 (cor rosa) ao dia 8 (cor marrom) de armazenamento resfriado associado a deterioração do alimento.

É importante ressaltar que apesar dos compostos bioativos em resíduos agroindustriais usualmente apresentarem bioatividade, nem sempre os filmes adicionados desses resíduos a manterão. Luchese et al. (2021) observaram que apesar da riqueza de compostos bioativos nos resíduos de laranja sob a forma de pó e extrato aquoso, somente o resíduo em pó apresentou um pequeno halo de inibição contra Staphylococcus aureus, porém não foi suficiente para conferir atividade antimicrobiana aos filmes desenvolvidos, provavelmente devido à baixa concentração de compostos antimicrobianos presentes no filme e/ou à sua não disponibilidade ou adequada difusão na matriz polimérica. Para além deste resultado, os autores evidenciaram migração de compostos dos filmes em soluções simuladoras de alimentos aquosos e gordurosos, no qual o filme contendo extrato aquoso dos resíduos de laranja apresentou migração mais acentuada em solução de ácido acético (simulador de alimento aquoso), reforçando potencial uso deste filme como embalagem ativa. Adicionalmente Luchese et al. (2021) avaliaram a capacidade de biodegradação destes filmes pelo método de soil burial. Desde a primeira semana em que as amostras de filmes com incorporação de resíduos estavam enterradas em solo sob condições laboratoriais, observou-se sinais qualitativos de desintegração, em especial nos filmes incorporados do extrato aquoso dos resíduos de laranja em comparação com aqueles incorporados de pó dos resíduos, devido à maior solubilidade em água desses filmes. Por outro lado, as amostras do filme controle (sem os resíduos de laranja), iniciaram um processo visível de desintegração somente a partir da terceira semana de teste, sugerindo, portanto, que o uso de resíduos agroindustriais não só pode ser benéfico para o desenvolvimento de filmes ativos, mas também são capazes de melhorar a biodegradabilidade do material. A incorporação de resíduos em filmes de amido pode conferir maior hidrofilicidade e componentes de baixa massa molar que são degradados mais rapidamente do que o amido (Luchese et al., 2021).

Otoni et al. (2018) investigaram a biodegradação aeróbia no solo de filmes de hidroxipropilmetilcelulose reforçados com celulose advinda de resíduos de processamento de cenoura, que apresentaram maior taxa de biodegradação $( \pm 60 \mathrm{~mL}$ de $\mathrm{CO}_{2}$ acumulado) durante 75 dias de análise em comparação com filme controle ( $\pm 20 \mathrm{~mL}$ de $\mathrm{CO}_{2}$ acumulado). Neto et al. (2018) 
desenvolveram um filme à base de amido termoplástico do fruto da pupunheira biodegradável, no qual observou-se, pelo método soil burial, elevada perda de massa total do filme $(84,4 \%)$ ao longo de apenas 18 semanas. Bagde e Nadanathangam (2019) evidenciaram elevada taxa de biodegradação em 2 meses para todos os filmes ativos à base de amido de milho desenvolvidos, porém a adição de bacteriocinas e de nanocelulose cristalina nas formulações filmogênicas estiveram associadas, respectivamente, à redução $( \pm 11,2 \%)$ e ao aumento $( \pm 4,8 \%)$ da taxa de biodegradação quando comparado ao filme controle (somente amido). Apesar das bacteriocinas terem afetado os microorganismos no solo responsáveis pela degradação, os filmes ativos continuaram biodegradáveis. Assis et al. (2018) observaram que as nanocápsulas de beta-caroteno (extraído de cenouras) incorporadas em filmes ativos à base de amido de mandioca não comprometeram a biodegradabilidade do material, apresentando uma média de perda de massa total das amostras de filmes de 60\% em 15 dias (método soil burial). Iahnke et al. (2015a) evidenciaram a biodegradabilidade de filmes à base de resíduos de beterraba e de cápsulas de gelatina, observando elevada perda de massa (mais de 75\%) após 15 dias de análise pelo método soil burial. Sanches et al. (2021) observaram rápida capacidade de biodegradação em filmes de amido adicionados de resíduos agroindustriais de jabuticaba pelo método soil burial, cuja média de perda de peso foi de cerca de 38,6\% em 15 dias. Os autores sugeriram que os componentes hidrofílicos dos filmes, ao absorverem água, favorecem o desenvolvimento de micro-organismos do solo que, por sua vez potencializam o uso dos biopolímeros presentes no filme como fonte energética. Assim, há certa instabilidade nas interações intermoleculares da matriz polimérica e desintegração dos filmes (Sanches et al., 2021). Esses estudos corroboram com a hipótese de que filmes à base de vegetais e seus resíduos apresentam grande potencial para aplicação como embalagem não só ativa, mas também biodegradável para alimentos, sendo, portanto, uma alternativa mais sustentável ao meio ambiente do que os plásticos convencionais.

\section{Perspectivas e Considerações Finais sob a Ótica da Economia Circular}

A necessidade de reduzir a geração de resíduos alimentares é evidente, uma vez que acarreta impactos ambientais, socioeconômicos e nutricionais, e é reforçada por algumas metas estabelecidas pelos ODS da ONU. A estratégia de aproveitamento destes resíduos para a produção de produtos de maior valor agregado, como filmes biodegradáveis, está inserida nos preceitos da economia circular. Além disso, valorizar resíduos agroindustriais gerados em grande volume no Brasil faz-se necessário já que pode colaborar para o manejo mais adequado dessas perdas de alimentos e propiciar ganhos socioeconômico ambientais. A viabilidade de valorização destes resíduos como filmes biodegradáveis decorre da ampla e heterogênea composição química, rica em biopolímeros, tais como amido, celulose e pectina. Ademais, a presença de compostos bioativos nos resíduos alimentares contribui para o desenvolvimento de filmes ativos, além de potencialmente biodegradáveis. A urgência em ampliar as alternativas de plásticos mais sustentáveis foi reforçada pelo uso intensificado de plásticos de origem fóssil na pandemia de COVID-19, em especial embalagens descartáveis para alimentos. No entanto, observa-se que os consumidores estão mais conscientes quanto às problemáticas do uso excessivo desses plásticos convencionais, contribuindo para impulsionar o crescimento do nicho mercadológico referente aos bioplásticos. Complementarmente, maiores investigações sobre filmes biodegradáveis à base de resíduos agroindustriais têm sido realizadas com enfoque no desenvolvimento de materiais que sejam mais competitivos com os plásticos tradicionais. Nesse sentido, com o intuito de reforçar esses materiais de embalagem, a nanotecnologia tem sido amplamente empregada, contribuindo para a melhoria das propriedades mecânicas, de barreira e térmicas de filmes nanocompósitos. No entanto, ressalta-se que maiores esforços devem ser realizados a fim de ampliar a escala de processo para viabilizar o desenvolvimento e a produção de filmes e nanocompósitos ativos e biodegradáveis industrialmente. Vale mencionar que a megadiversidade que marca o território do Brasil, aliado ao seu conhecimento tecnológico acumulado e a uma base industrial diversificada tornam o país um atrativo para novos modelos de negócios que priorizem o uso otimizado de recursos naturais e que tenham processos mais verdes, podendo assumir uma posição de liderança na economia circular enquanto nação. Em adição, regulamentações governamentais devem ser discutidas e implementadas para maiores avanços na área de 
embalagens sustentáveis, inclusive reforçando a importância da rotulagem verde como instrumento fiscalizador e conscientizador.

\section{Referências}

Acquavia, M. A., Pascale, R., Martelli, G., Bondoni, M., \& Bianco, G. (2021). Natural polymeric materials: a solution to plastic pollution from the agro-food sector. Polymers, 13(158). https://doi.org/10.3390/polym13010158

Almasi, H., Oskouie, M. J., \& Saleh, A. (2020). A review on techniques used for design of controlled release food active packaging. Critical Reviews in Food Science and Nutrition. https://doi.org/10.1080/10408398.2020.1783199

Andrade, C. J. A., Simiqueli, A. P. R., Lima, F. A., Silva, J. B., Andrade, L. M., \& Fai, A. E. C. (2017). Cassava wastewater as substrate in biotechnological processes. Handbook on cassava. Production, potential uses and recent advances (pp. 171-199). Nova Science Publishers.

Andrade, M. R., Nery, T. B. R., Santana, T. I. S., Leal, I. L., Rodrigues, L. A. P., Reis, J. H. O., Druzian, J. I., \& Machado, B. A. S. (2019). Effect of cellulose nanocrystals from different lignocellulosic residues to chitosan/glycerol films. Polymers, 11(4), 658. https://doi.org/10.3390/polym11040658

Andretta, R., Luchese, C. L., Tessaro, I. C., \& Spada, J. C. (2019). Development and characterization of pH-indicator films based on cassava starch and blueberry residue by thermocompression. Food Hydrocolloids, 93, 317-324. https://doi.org/10.1016/j.foodhyd.2019.02.019

Arquelau, P. B. F., Silva, V. D. M., Garcia, M. A. V. T., Araújo, R. L. B., \& Fante, C. A. (2019). Characterization of edible coatings based on ripe "Prata" banana peel flour. Food Hydrocolloids, 89, 570-578. https://doi.org/10.1016/j.foodhyd.2018.11.029

Arun, K. B., Madhavan, A., Sindhu, R., Binod, P., Pandey, A., \& Sirohi, R. R. R. (2020). Remodeling agro-industrial and food wastes into value-added bioactives and biopolymers. Industrial Crops and Products, 154, 112621. https://doi.org/10.1016/j.indcrop.2020.112621

Assis, R. Q., Pagno, C. H., Costa, T. M. H., Flôres, S. H., Rios, A. O. (2018). Synthesis of biodegradable films based on cassava starch containing free and nanoencapsulated $\beta$-carotene. Packaging Technology and Science. https://doi.org/10.1002/pts.2364

Ates, B., Koytepe, S., Ulu, A., Gurses, C., \& Thakur, V. K. (2020). Chemistry, structures, and advanced applications of nanocomposites from biorenewable resources. Chemical Reviews. https://doi.org/10.1021/acs.chemrev.9b00553

Avila, L. B., Barreto, E. R. C., Souza, P. K., Silva, B. Z., Martiny, T. R., Moraes, C. C., Morais, M. M., Raghavan, V., \& Rosa, G. S. (2020). Carrageenan-based films incorporated with jaboticaba peel extract: an innovative material for active food packaging. Molecules, 25 , 5563. https://doi.org/10.3390/molecules25235563

Azeredo, H. M., Rosa, M. F., \& Mattoso, L. H. C. (2017). Nanocellulose in bio-based food packaging applications. Industrial Crops and Products, 97, 664-671. https://doi.org/10.1016/j.indcrop.2016.03.013

Azevedo, L. C., Rovani, S., Santos, J. J., Dias, D. B., Nascimento, S. S., Oliveira, F. F., Silva, L., \& Fungaro, D. A. (2020). Biodegradable films derived from corn and potato starch and study effect of silicate extracted from sugarcane waste ash. ACS Applied Polymer Materials, 2(6), 2160-2169. https://doi.org/10.1021/acsapm.0c00124

Bagde, P., Vigneshwaran, N. (2019). Mechanical, antibacterial and biodegradable properties of starch film containing bacteriocin immobilized crystalline nanocellulose. Carbohydrate Polymers, 222, 115021. https://doi.org/10.1016/j.carbpol.2019.115021

Balakrishnan, P., Sreekala, M. S., Kunaver, M., Huskić, M., \& Thomas, S. (2017). Morphology, transport characteristics and viscoelastic polymer chain confinement in nanocomposites based on thermoplastic potato starch and cellulose nanofibers from pineapple leaf. Carbohydrate Polymers, $169,176-188$. https://doi.org/10.1016/j.carbpol.2017.04.017

Banerjee, J., Singh, R., Vijayaraghavan, R., Macfarlane, D., Patti, A. F., \& Arora, A. (2017). Bioactives from fruit processing wastes: green approaches to valuable chemicals. Food Chemistry, 225, 10-22. https://doi.org/10.1016/j.foodchem.2016.12.093

Barone, A. S., Matheus, J. R. V., Souza, T. S. P., Moreira, R. F. A., \& Fai, A. E. C. (2021). Green-based active packaging: opportunities beyond COVID-19, food applications and perspectives in circular economy - a brief review. Comprehensive Reviews in Food Science and Food Safety, 2021, 1-25. https://doi.org/10.1111/1541-4337.12812

Barros-Alexandrino, T. T., Tosi, M. M., \& Assis, O. B. G. (2018). Comparison between chitosan nanoparticles and cellulose nanofibers as reinforcement fillers in papaya puree films: effects on mechanical, water vapor barrier, and thermal properties. Polymer Engineering \& Science, 59(S1), E287-E292. https://doi.org/10.1002/pen.24938

Bhardwaj, A., Alam, T., \& Talwar, N. (2019). Recent advances in active packaging of agri-food products: a review. Journal of Postharvest Technology, 7(1), 33-62.

Bhargava, N., Sharanagat, V. S., Mor, R. S., \& Kumar, K. (2020). Active and intelligent biodegradable packaging films using food and food waste-derived bioactive compounds: a review. Trends in Food Science and Technology, 105, 385-401. https://doi.org/10.1016/j.tifs.2020.09.015

Brito, T. B. N., Ferreira, M. S. L, \& Fai, A. E. C. (2020). Utilization of agricultural by-products: bioactive properties and technological applications. Food Reviews International. https://doi.org/10.1080/87559129.2020.1804930

Brito, T. B., Carrajola, J. F., Gonçalves, E. C. B. A., Martelli-Tosi, M., \& Ferreira, M. S. L. (2019). Fruit and vegetable residues flours with different granulometry range as raw material for pectin-enriched biodegradable film preparation. Food Research International, 121, 412-421. https://doi.org/10.1016/j.foodres.2019.03.058 
Buckle K. (2015). Can food science reduce world hunger? Food security and food safety for the twenty-first century. Springer. https://doi.org/10.1007/978-981287-417-7_1

Caetano, K. S., Lopes, N. A., Costa, T. M. H., Brandelli, A., Rodrigues, E., Flôres, S. H., \& Cladera-Oliveira, F. (2018). Characterization of active biodegradable films based on cassava starch and natural compounds. Food Packaging and Shelf Life, 16, 138-147. https://doi.org/10.1016/j.fpsl.2018.03.006

Capello, C., Trevisol, T. C., Pelicioli, J., Terrazas, M. B., Monteiro, A. R., \& Valencia, G. A. (2021). Preparation and characterization of colorimetric indicator films based on chitosan/polyvinyl alcohol and anthocyanins from agri-food wastes. Journal of Polymers and the Environment, 29, 1616-1629. https://doi.org/10.1007/s10924-020-01978-3

Carpes, S. T., Bertotto, C., Bilck, A. P., Yamashita, F., Anjos, O., Siddique, M. A. B., Harrison, S. M., \& Brunton, N. P. (2021). Bio-based films prepared with apple pomace: Volatiles compound composition and mechanical, antioxidant and antibacterial properties. LWT - Food Science and Technology, $144,111241$. https://doi.org/10.1016/j.1wt.2021.111241

Carvalho, G. R., Marques, G. S., Jorge, L. M. M., Jorge, R. M. M. (2018). Cassava bagasse as a reinforcement agent in the polymeric blend of biodegradable films. Journal of Applied Polymer Science, 136(12), 47224. https://doi.org/10.1002/app.47224

Chan, J. X., Wong, J. F., Hassan, A., \& Zakaria, Z. (2021). Bioplastics from agricultural waste. Biopolymers and Biocomposites from Agro-Waste for Packaging Applications. Woodhead Publishing Series in Composites Science and Engineering, (pp. 141-169). https://doi.org/10.1016/B978-0-12-819953-4.00005-7

Chen, J., Wang, X., Long, Z., Wang, S., Zhang, J., Wang, L. (2020). Preparation and performance of thermoplastic starch and microcrystalline cellulose for packaging composites: Extrusion and hot pressing. International Journal of Biological Macromolecules, 165, $2295-2302$. https://doi.org/10.1016/j.ijbiomac.2020.10.117

Chisenga, S. M., Tolesa, G. N., Workneh, T. S., \& Owusu-Kwarteng, James. (2020). Biodegradable food packaging materials and prospects of the fourth industrial revolution for tomato fruit and product handling. International Journal of Food Science, 8879101. https://doi.org/10.1155/2020/8879101

Chisenga, S. M., Workneh, T. S., Bultosa, G., \& Alimi, B. A. (2019). Progress in research and applications of cassava flour and starch: a review. Journal of Food Science and Technology. https://doi.org/10.1007/s13197-019-03814-6

Chong, T. Y., Law, M. C., \& Chan, Y. S. (2020). The potentials of corn waste lignocellulosic fibre as an improved reinforced bioplastic composites. Journal of Polymers and the Environment, 29, 363-381. https://doi.org/10.1007/s10924-020-01888-4

Coelho, C. C. S., Michelin, M., Cerqueira, M. A., Gonçalves, C., Tonon, R. V., Pastrana, L. M., Freitas-Silva, O., Vicente, A. A., Cabral, L. M. C., \& Teixeira, J. A. (2018). Cellulose nanocrystals from grape pomace: production, properties and cytotoxicity assessment. Carbohydrate Polymers, 192, 327-336. https://doi.org/10.1016/j.carbpol.2018.03.023

Coelho, C. C. S., Silva, R. B. S., Carvalho, C. W. P., et al. (2020). Cellulose nanocrystals from grape pomace and their use for the development of starch-based nanocomposite films. International Journal of Biological Macromolecules. https://doi.org/10.1016/j.ijbiomac.2020.05.046

Corrado, S., Ardente, F., Sala, S., \& Saouter, E. (2017). Modelling of food loss within life cycle assessment: From current practice towards a systematization. Journal of Cleaner Production, 140, 847-859. https://doi.org/10.1016/j.jclepro.2016.06.050

Costa, J. C. M., Miki, K. S. L., Ramos, A. S., \& Teixeira-Costa, B. E. (2020). Development of biodegradable films based on purple yam starch/chitosan for food application. Heliyon, 6(4), e03718. https://doi.org/10.1016/j.heliyon.2020.e03718

Costa, L. A., Diógenes, I. C. N., Oliveira, M. A., Ribeiro, A. F., Furtado, R. F., Bastos, M. S. R., Silva, M. A. S., \& Benevides, S. D. (2021). Smart film of jackfruit seed starch as a potential indicator of fish freshness. Food Science and Technology, 41(2). https://doi.org/10.1590/fst.06420

Crizel, T. M., Haas Costa, T. M., De Oliveira, A. R., \& Flôres, S. H. (2016). Valorization of food-grade industrial waste in the obtaining active biodegradable films for packaging. Industrial Crops and Products, 87, 218-228. http://dx.doi.org/10.1016/j.indcrop.2016.04.039

Crizel, T. M., Rios, A. D. O., Alves, V. D., Bandarra, N., Moldão-Martins, M., \& Flôres, S. H. (2018). Biodegradable films based on gelatin and papaya peel microparticles with antioxidant properties. Food and Bioprocess Technology, 11, 536-550. https://doi.org/10.1007/s11947-017-2030-0

Da Silva, D. C., Lopes, I. A., Da Silva, L. J. S., Lima, M. F., Barros Filho, A. K. D., Villa-Vélez, H. A., \& Santana, A. A. (2019). Physical properties of films based on pectin and babassu coconut mesocarp. International Journal of Biological Macromolecules, 130, 419-428, https://doi.org/10.1016/j.ijbiomac.2019.02.151

Dal' Magro, G. P., \& Talamini, E. (2019). Estimating the magnitude of the food loss and waste generated in Brazil. Waste Management \& Research: The Journal for a Sustainable Circular Economy, 37(7), 706-716. https://doi.org/10.1177/0734242X19836710

Dantas, E. A., Costa, S. S., Cruz, L. S., Bramont, W. B., Costa, A. S., Padilha, F. F., Druzian, J. I., \& Machado, B. A. S. (2015). Caracterização e avaliação das propriedades antioxidantes de filmes biodegradáveis incorporados com polpas de frutas tropicais [Characterization and evaluation of the antioxidant properties of biodegradable films incorporated with tropical fruit pulps]. Ciência Rural, 45(1), 142-148. https://doi.org/10.1590/0103-8478cr20131458

Engel, J. B., Ginity, M. M., Luchese, C. L., Tessaro, I. C., \& Spada, J. C. (2020). Reuse of diferent agroindustrial wastes: pinhão and pecan nutshells incorporated into biocomposites using thermocompression. Journal of Polymers and the Environment, 28, 1431-1440. https://doi.org/10.1007/s10924-020-01696-w

Evangelho, J. A., Dannenberg, G. S., Biduski, B., Halal, S. L. M., Kringel, D. H., Gularte, M. A., Fiorentini, A. M., \& Zavareze, E. R. (2019). Antibacterial activity, optical, mechanical, and barrier properties of corn starch films containing orange essential oil. Carbohydrate Polymers, $222,114981$. https://doi.org/10.1016/j.carbpol.2019.114981

Fai, A. E. C., Souza, M. R. A., Barros, S. T., Bruno, N. V., Ferreira, M. S. L., \& Gonçalves, E. C. B. A. (2016). Development and evaluation of biodegradable films and coatings obtained from fruit and vegetable residues applied to fresh-cut carrot (Daucus carota L.). Postharvest Biology and Technology, 112, 194204. http://dx.doi.org/10.1016/j.postharvbio.2015.09.021 
Fanzo, J., Hood, A., \& Davis, C. (2020). Eating our way through the Anthropocene. Physiology \& Behavior, 222, 112929. https://doi.org/10.1016/j.physbeh.2020.112929

FAO. (2011). Global food losses and food wastes: extent, causes and prevention. Rome, <http://www.fao.org/3/i2697e/i2697e.pdf>.

FAO. (2014). Mitigation of Food Wastage - Societal Costs and Benefits. Rome, FAO. <http://www.fao.org/3/i3989e/i3989e.pdf>.

FAO. (2015). Food wastage footprint \& Climate Change. Rome, FAO. <http://www.fao.org/3/bb144e/bb144e.pdf>.

FAO. (2019). Key Facts on Food Loss and Waste You Should Know! <http://www.fao.org/3/i2697e/i2697e.pdf〉.

Faria, L. U. S., Pacheco, B. J. S., Oliveira, G. C., \& Silva, J. L. S. (2020). Production of cellulose nanocrystals from pineapple crown fibers through alkaline pretreatment and acid hydrolysis under different conditions. Journal of Materials Research and Technology, 9(6), 12346-12353. https://doi.org/10.1016/j.jmrt.2020.08.093

Faustino, M., Veiga, M., Sousa, P., Costa, E. M., Silva, S., \& Pintado, M. (2019). Agro-food byproducts as a new source of natural food additives. Molecules, 24(6), 1056. https://doi.org/10.3390/molecules24061056

Fidelis, M., De Moura, C., Kabbas, T., Pap, N., Mattila, P., Mäkinen, S., Putnik, P., Kovačević, D. B., Tian, Y., Yang, B. Y., \& Granato, D. (2019). Fruit seeds as sources of bioactive compounds: sustainable production of high value-added ingredients from by-products within circular economy. Molecules, $24(21), 3854$. https://doi.org/10.3390/molecules24213854

Fitch-Vargas, P. R., Aguilar-Palazuelos, E., Zazueta-Morales, J. J., Vega-García, M. O., Valdez-Morales, J. E., Martínez-Bustos, F., Jacobo-Valenzuela, N. (2016). Physicochemical and microstructural characterization of corn starch edible films obtained by a combination of extrusion technology and casting technique. Journal of Food Science, 81(9), E2224 - E2232. https://doi.org/10.1111/1750-3841.13416

Foundation, E. M. (2021). New Plastics Economy. Disponível em: <https://www.ellenmacarthurfoundation.org/our-work/activities/new-plastics-economy>. Acesso em: 14 de julho de 2021

FORBES. (2021). Quem diria, travestida de embalagem, a mandioca está cada vez mais em alta. Disponível em: <https://forbes.com.br/forbesesg/2021/05/quemdiria-travestida-de-embalagem-a-mandioca-esta-cada-vez-mais-em-alta/>. Acesso em: 13 de maio de 2021.

Freitas, P. A. V., Silva, R. R. A., de Oliveira, T. V., Soares, R. R. A., Junior, N. S., Moraes, A. R. F., Pires, A. C. D. S., \& Soares, N. F. F. (2020). Development and characterization of intelligent cellulose acetate-based films using red cabbage extract for visual detection of volatile bases. LWT - Food Science and Technology, 132, 109780. https://doi.org/10.1016/j.1wt.2020.109780

Fu, L., Zhu, J., Zhang, S., Li, X., Zhang, B., Pu, H., Li, L., Wang, Q. (2018). Hierarchical structure and thermal behavior of hydrophobic starch-based films with different amylose contents. Carbohydrate Polymers, 181, 528-535. https://doi.org/10.1016/j.carbpol.2017.12.010

Geyer, R., Jambeck, J. R., \& Law, K. L. (2017). Production, use, and fate of all plastics ever made. Science Advances., 3(7), e1700782. https://doi.org/10.1126/sciadv.1700782

Guo, Z., Ge, X., Li, W., Yang, L., Han, L., Yu, Q-L. (2021). Active-intelligent film based on pectin from watermelon peel containing beetroot extract to monitor the freshness of packaged chilled beef. Food Hydrocolloids, 119, 106751. https://doi.org/10.1016/j.foodhyd.2021.106751

Gustavsson, J., Cederberg, C., Sonesson, U., Otterdijk, R. V., \& Meybeck, A. (2011). Global food losses and food waste - extent, causes and prevention, food loss and food waste: causes and solutions. Food and Agriculture Organization of the United Nations (FAO), Rome. https://doi.org/10.4337/9781788975391

Hall, D. (2017). The Guardian. Throwaway culture has spread packaging waste worldwide: here's what to do about it. Disponível em: <https://www.theguardian.com/environment/2017/mar/13/waste-plastic-food-packaging-recycling-throwaway-culture-dave-hall>. Acesso em: 11 de julho de 2021

Hornung, P. S., Ávila, S., Apea-Bah, F. B., Liu, J., Teixeira, G. L., Ribani, R. H., \& Beta, T. (2020). Sustainable use of Ilex paraguariensis waste in improving biodegradable corn starch films' mechanical, thermal and bioactive properties. Journal of Polymers and the Environment, 28 , 1696-1709. https://doi.org/10.1007/s10924-020-01723-w

Huang, L., Zhao, H., Yi, T., Qi, M., Xu, H., Mo, Q., Huang, C., Wang, S., \& Liu, Y. (2020). Preparation and properties of cassava residue cellulose nanofibril/cassava starch composite films. Nanomaterials, 10(4), 755. https://doi.org/10.3390/nano10040755

Iahnke, A. O. S., Costa, T. M. H., Rios, A. O., \& Flôres, S. H. (2015b). Residues of minimally processed carrot and gelatin capsules: potential materials for packaging films. Industrial Crops and Products, 76, 1071-1078. http://dx.doi.org/10.1016/j.indcrop.2015.08.025

Iahnke, A. O. S., Costa, T. M. H., Rios, A. O., \& Flôres, S. H. (2015a). Antioxidant films based on gelatin capsules and minimally processed beet root (Beta vulgaris L. var. Conditiva) residues. Journal of Applied Polymer Science, 133(10). https://doi.org/10.1002/app.43094

Jácome, M. C. M. B., Padilha, C. E. A., Arrais, M. R. N., Leitão, A. L. O. S., Júnior, F. C. S., \& Santos, E. S. (2020). Valorization of mangaba residue (Hancornia speciosa Gomes) for polygalacturonase production from Aspergillus niger IOC 4003 and fabrication of active chitosan films. Biomass Conversion and Biorefinery. https://doi.org/10.1007/s13399-020-01102-4

Jiménez-Moreno, N., Esparza, I., Bimbela, F., Gandía, L. M., \& Ancín-Azpilicueta, C. (2020). Valorization of selected fruit and vegetable wastes as bioactive compounds: Opportunities and challenges. Critical Reviews in Environmental Science and Technology, 50(20), 2061-2108. https://doi.org/10.1080/10643389.2019.1694819

Jirukkakul, N. (2016). The study of edible film production from unriped banana flour and riped banana puree. International Food Research Journal, 23(1), 95101. 
Jurgilevich, A., Birge, T., Kentala-Lehtonen, J., Korhonen-Kurki, K., Pietiäinen, J., Saikku, L, \& Schösler. H. (2016). Transition towards circular economy in the food system. Sustainability, 8, 69. https://doi.org/10.3390/su8010069

Lemaire, A., \& Limbourg, S. (2019). How can food loss and waste management achieve sustainable development goals? Journal of Cleaner Production, 234, 1221-1234. https://doi.org/10.1016/j.jclepro.2019.06.226

Luchese, C. L., Abdalla, V. F., Spada, J. C., Tessaro, I. C. (2018). Evaluation of blueberry residue incorporated cassava starch film as pH indicator in different simulants and foodstuffs. Food hydrocolloids, 82, 209-218. https://doi.org/10.1016/j.foodhyd.2018.04.010

Luchese, C. L., Pavoni, J. M. F., \& Tessaro, I. C. (2021). Infuence of the incorporation form of waste from the production of orange juice in the properties of cassava starch-based films. Food Hydrocolloids, 117, 106730. https://doi.org/10.101F/j.foodhyd.2021.10F7G0

Luchese, C. L., Pavoni, J. M. F., Spada, J. C., \& Tessaro, I. C. (2019). Influence of blueberry and jaboticaba agroindustrial residue particle size on color change of corn starch-based films submitted to different pH values solutions. Journal of Renewable Materials, 7(3), 235-243. https://doi.org/10.32604/jrm.2019.00033

Luttenberger, L. R. (2019). Circular economy and food packaging/food nexus. In: International Conference MATRIB, Vela Luka.

Maniglia, B. C., \& Tapia-Blácido, D. R. (2019). Structural modification of fiber and starch in turmeric residue by chemical and mechanical treatment for production of biodegradable films. International Journal of Biological Macromolecules, 126, 507-516. https://doi.org/10.1016/j.ijbiomac.2018.12.206

Maraveas, C. (2020). Production of sustainable and biodegradable polymers from agricultural waste. Polymers, 12(5), 1127. https://doi.org/10.3390/polym12051127

Martelli, M. R., Barros, T. T., \& Assis, O. B. G. (2014). Filmes de polpa de banana produzidos por batelada: propriedades mecânicas e coloração [Puree films from bananas processed in the batching mode: mechanical properties and coloring variations]. Polímeros: Ciência e Tecnologia, 24(1), 137-142. http://dx.doi.org/10.4322/polimeros.2014.062

Martelli-Tosi, M., Assis, O. B. G., Silva, N. C., Esposto, B. S., Martins, M. A., \& Tapia-Blácido, D. R. (2017). Chemical treatment and characterization of soybean straw and soybean protein isolate/straw composite films. Carbohydrate Polymers, 157, 512-520. http://dx.doi.org/10.1016/j.carbpol.2016.10.013

Martelli-Tosi, M., Masson, M. M., Silva, N. C., Esposto, B. S., Barros, T. T., Assis, O. B.G., \& Tapia-Blácido, D. R. (2018). Soybean straw nanocellulose produced by enzymatic or acid treatment as a reinforcing filler in soy protein isolate films. Carbohydrate Polymers, 198, 61-68. https://doi.org/10.1016/j.carbpol.2018.06.053

Martins, M. P., Dagostin, J. L. A., Franco, T. S., Muñiz, G. I. B., \& Masson, M. L. (2020). Application of cellulose nanofibrils isolated from an agroindustrial residue of peach palm in cassava starch films. Food Biophysics, 15, 323-334. https://doi.org/10.1007/s11483-020-09626-y

Matheus, J. R. V., Assis, R. M., Correia, T. R., Marques, M. R. C., Leite, M. C. A. M., Pelissari, F. M., Miyahira, R. F., \& Fai, A. E. C. (2021b). Biodegradable and edible film based on persimmon (Diospyros kaki L.) used as a lid for minimally processed vegetables packaging. Food and Bioprocess Technology, 14, 765779. https://doi.org/10.1007/s11947-021-02595-1

Matheus, J. R. V., Miyahira, R. F., \& Fai, A. E. C. (2021a). Biodegradable films based on fruit puree: a brief review. Critical Reviews in Food Science and Nutrition, 61(12), 2090-2097. https://doi.org/10.1080/10408398.2020.1772715

Melo, P. E. F., Silva, A. P. M., Marques, F. P., Ribeiro, P. R. V., Filho, M. S. M. S., Brito, E. S., Lima, J. R., \& Azeredo, H. M. C. (2019a). Antioxidant films from mango kernel components. Food Hydrocolloids, 95, 487-495. https://doi.org/10.1016/j.foodhyd.2019.04.061

Melo, P. T. S., Nunes, J. C., Otoni, C. G., Aouada, F. A., \& Moura, M. R. (2019b). Combining cupuassu (Theobroma grandiflorum) puree, pectin, and chitosan nanoparticles into novel edible films for food packaging applications. Journal of Food Science. https://doi.org/10.1111/1750-3841.14685

Mellinas, C., Ramos, M., Jiménez, A., \& Garrigós, M. C. (2020). Recent trends in the use of pectin from agro-waste residues as a natural-based biopolymer for food packaging applications. Materials, 13(3), 673. https://doi.org/10.3390/ma13030673

Mendes, J. F., Norcino, L. B., Manrich, A., Pinheiro, A. C. M., Oliveira, J. E., \& Mattoso, L. H. C. (2020). Development, physical-chemical properties, and photodegradation of pectin film reinforced with malt bagasse fibers by continuous casting. Journal Applied Polimer Science, 137(39), 49178. https://doi.org/10.1002/app.49178

Mendes, N. S., Santos, M. C. P., Seljan, M. P., Silva, F. C., Coimbra, P. P. S., Souza, J. D. R. P., Fai, A. E. C., Kawaguti, H. Y., Moreira, S. G., Gonçalves, E. C. B. A. (2020). Characterization and utilization of fruit and vegetable residue flour for the development of functional foods. Research, Society and Development, 9(12), e43191211034. https://doi.org/10.33448/rsd-v9i12.11034

Meys, R., Frick, F., Westhues, S., Sternberg, A., Klankermayer, J., \& Bardow, A. (2020). Towards a circular economy for plastic packaging wastes - the environmental potential of chemical recycling. Resources, Conservation and Recycling, 162, 105010. https://doi.org/10.1016/j.resconrec.2020.105010

Moro, T. M. A., Ascheri, J. L. R., Ortiz, J. A. R., Carvalho, C. W. P., \& Meléndez-Arévalo, A. (2017). Bioplastics of native starches reinforced with passion fruit peel. Food and Bioprocess Technology. https://doi.org/10.1007/s11947-017-1944-X

Munhoz, D. R., Moreira, F. K., Bresolin, J. D., Bernardo, M. P., Sousa, C. P., \& Mattoso, L. H. (2018). Sustainable production and in vitro biodegradability of edible films from yellow passion fruit co-products via continuous casting. ACS Applied Polymer Materials, 6(8), 9883-9892. http://dx.doi.org/10.1021/acssuschemeng.8b01101

Murray, A., Skene, K., \& Haynes, K. (2017). The circular economy: an interdisciplinary exploration of the concept and application in a global context. Journal of Business Ethics, 140(3), 369-380. https://doi.org/10.1007/s10551-015-2693-2

Nascimento, J. A. A., Santos, A. F., Silva, I. D. L., Falcão, E. H. L., Britto, D., \& Vinhas, G. M. (2021). Physico-chemical, mechanical and morphological properties of biodegradable films based on arrowroot starch and poly(vinyl alcohol). Journal of Macromolecular Science, Part B-Physics, 6. https://doi.org/10.1080/00222348.2021.1949836 
Neto, B. A. M., Junior, C. C. M. F., Silva, E. G. P., Franco, M., Santos Reis, N., Ferreira Bonomo, R. C., Almeida, P. F., \& Pontes, K. V. (2018). Biodegradable thermoplastic starch of peach palm (Bactris gasipaes kunth) fruit: production and characterization. International Journal of Food Properties. https://doi.org/10.1080/10942912.2017.1372472

Nogueira, J. F., Soares, C. T., Cavasini, R., Fakhouri, F. M., P de Oliveira, R. A. (2019). Bioactive films of arrowroot starch and blackberry pulp: Physical, mechanical and barrier properties and stability to $\mathrm{pH}$ and sterilization. Food Chemistry, 275, 417-425. https://doi.org/10.101F/j.foodchem.2018.0B.054

Oldoni, F. C. A., Bernardo, M. P., Filho, J. G. O., Aguiar, A. C., Moreira, F. K. V., Mattoso, L. H. C., Colnago, L. A., \& Ferreira, M. D. (2021). Valorization of mangoes with internal breakdown through the production of edible films by continuous solution casting. LWT - Food Science and Technology, 145, 111339. https://doi.org/10.1016/j.lwt.2021.111339

Oliveira, D. A., Angonese, M., Ferreira, S. R. S., \& Gomes, C. L. (2017). Nanoencapsulation of passion fruit by-products extracts for enhanced antimicrobial activity. Food and Bioproducts Processing, 104, 137-146. https://doi.org/10.1016/j.fbp.2017.05.009

Omran, A. A. B., Mohammed, A. A. B. A., Sapuan, S. M., Ilyas, R. A., Asyraf, M. R. M., Rahimian Koloor, S. S., \& Petru, M. (2021). Micro- and nanocellulose in polymer composite materials: a review. Polymers, 13. https://doi.org/10.3390/ polym13020231

ONU. (2015). Transforming Our World: The 2030 Agenda for Sustainable Development United Nations, p. 1-35. < https://sdgs.un.org/2030agenda>.

Otoni, C. G., Avena-Bustillos, R. J., Azeredo, H. M. C., Lorevice, M. V., Moura, M. R., Mattoso, L. H. C., \& McHugh, T. H. (2017). Recent advances on edible films based on fruits and vegetables - a review. Comprehensive Reviews in Food Science and Food Safety, 16, 1151-1169. https://doi.org/10.1111/15414337.12281

Otoni, C.G., Lodi, B. D., Lorevice, M. V., Leitão, R. C., Ferreira, M. D., Moura, M. R., \& Mattoso, L. H.C. (2018). Optimized and scaled-up production of cellulose-reinforced biodegradable composite films made up of carrot processing waste. Industrial Crops and Products, 121, 66-72. https://doi.org/10.1016/j.indcrop.2018.05.003

Pagno, C. H., Costa, T. M. H., Menezes, E. W., Benvenutti, E. V., Hertz, P. F., Matte, C. R., Tosati, J. V., Monteiro, A. R., Rios, A. O., \& Flôres, S. H. (2015). Development of active biofilms of quinoa (Chenopodium quinoa W.) starch containing gold nanoparticles and evaluation of antimicrobial activity. Food Chemistry, 173, 755-762. https://doi.org/10.1016/j.foodchem.2014.10.068

Pakutsah, K., \& Aht-Ong, D. (2020). Facile isolation of cellulose nanofibers from water hyacinth using water-based mechanical defibrillation: Insights into morphological, physical, and rheological properties. International Journal of Biological Macromolecules, 145, 64-76. https://doi.org/10.1016/j.ijbiomac.2019.12.172

Pelissari, F. M., Andrade-Mahecha, M. M., Sobral, P. J. D. A., \& Menegalli, F. C. (2017). Nanocomposites based on banana starch reinforced with celulose nanofibers isolated from banana peels. Journal of Colloid and Interface Science, 505, 154-167. https://doi.org/10.1016/j.jcis.2017.05.106

Pelissari, F. M., Sobral, P. J. D. A., \& Menegalli, F. C. (2014). Isolation and characterization of cellulose nanofibers from banana peels. Cellulose, 21 , 417-32. PLASTICSEUROPE. (2020). Plastics - the Facts 2020. An analysis of European latest plastics production, demand and waste data. Disponível em: <https://www.plasticseurope.org/application/files/8016/1125/2189/AF_Plastics_the_facts-WEB-2020-ING_FINAL.pdf>. Acesso em: 09 de maio de 2021.

Porpino, G., Lourenço, C. E., Araújo, C.M., \& Bastos, A. (2018). Intercâmbio Brasil - União Europeia sobre desperdício de alimentos. Relatório final de pesquisa. Brasília: Diálogos Setoriais União Europeia - Brasil. < http:// www.sectordialogues.org/publicacao

Ranganathan, S., Dutta, S., Moses, J. A., \& Anandharamakrishnan, C. (2020). Utilization of food waste streams for the production of biopolymers. Heliyon, 6(9), e04891. https://doi.org/10.1016/j.heliyon.2020.e04891

Rodríguez, G. M., Sibaja, J. C., Espitia, P. J. P., Otoni, C. G. (2020). Antioxidant active packaging based on papaya edible films incorporated with Moringa oleifera and ascorbic acid for food preservation. Food Hydrocolloids, 103, 105630. https://doi.org/10.1016/j.foodhyd.2019.105630

Rodsamran, P, \& Sothornvit, R. (2019a). Lime peel pectin integrated with coconut water and lime peel extract as a new bioactive film sachet to retard soybean oil oxidation. Food Hydrocolloids, 97, 105173. https://doi.org/10.1016/j.foodhyd.2019.105173

Rodsamran, P, \& Sothornvit, R. (2019b). Preparation and characterization of pectin fraction from pineapple peel as a natural plasticizer and material for biopolymer film. Food and Bioproducts Processing, 118, 198-206. https://doi.org/10.1016/j.fbp.2019.09.010

Sá, N. M. S. M., Mattos, A. L. A., Silva, L. M. A., Brito, E. S., Rosa, M. F., \& Azeredo, H. M. C. (2020). From cashew byproducts to biodegradable active materials: bacterial cellulose-lignin-cellulose nanocrystal nanocomposite films. International Journal of Biological Macromolecules, 161, 1337-1345. https://doi.org/10.1016/j.ijbiomac.2020.07.269

Sanches, M. A. R., Camelo-Silva, C., Tussolini, L., Tussolini, M., Zambiazi, R. C., \& Pertuzatti, P. B. (2021). Development, characterization and optimization of biopolymers films based on starch and flour from jabuticaba (Myrciaria cauliflora) peel. Food Chemistry, 343 , 128430. https://doi.org/10.1016/j.foodchem.2020.128430

Santos, K. L., Panizzon, J., Cenci, M. M., Grabowski, G., \& Jahno, V. D. (2020). Food losses and waste: reflections on the current brazilian scenario. Brazilian Journal of Food Technology, 23, e2019134. https://doi.org/10.1590/1981-6723.13419

Santos, N. L., Braga, R. C., Bastos, M. S. R., Cunha, P. L. R., Mendes, F. R. S., Galvão, A. M. M. T., Bezerra, G. S., \& Passos, A. A. C. (2019). Preparation and characterization of Xyloglucan films extracted from Tamarindus indica seeds for packaging cut-up 'Sunrise Solo' papaya. International Journal of Biological Macromolecules, 132, 1163-1175. https://doi.org/10.1016/j.ijbiomac.2019.04.044

Sartori, T., \& Menegalli, F. C. (2016). Development and characterization of unripe banana starch films incorporated with solid lipid microparticles containing ascorbic acid. Food Hydrolloids, 55, 210-219. http://dx.doi.org/10.1016/j.foodhyd.2015.11.018 
Serrano-León, J. S., Bergamaschi, K. B., Yoshida, C. M. P., Saldaña, E., Selani, M. M., Rios-Mera, J. D., Alencar, S. M., \& Contreras-Castillo, C. J. (2018). Chitosan active films containing agro-industrial residue extracts for shelf life extension of chicken restructured product. Food Research International, 108, 93100. https://doi.org/10.1016/j.foodres.2018.03.031

Sganzerla, W. G., Ribeiro, C. P. P., Uliana, N. R., Rodrigues, M. B. C., Rosa, C. G., Ferrareze, J. P., Veeck, A. P. L., \& Nunes, M. R. (2021). Bioactive and pHsensitive films based on carboxymethyl cellulose and blackberry (Morus nigra L.) anthocyanin-rich extract: A perspective coating material to improve the shelf life of cherry tomato (Solanum lycopersicum L. var. cerasiforme). Biocatalysis and Agricultural Biotechnology, 33, 101989. https://doi.org/10.1016/j.bcab.2021.101989

Sganzerla, W. G., Rosa, G. B., Ferreira, A. L. A., Rosa, C. G., Beling, P. C., Xavier, L. O., Hansen, C. M., Ferrareze, J. P., Nunes, M. R., Barreto, P. L. M., \& Veeck, A. P. L. (2020). Bioactive food packaging based on starch, citric pectin and functionalized with Acca sellowiana waste by-product: characterization and application in the postharvest conservation of apple. International Journal of Biological Macromolecules, 147, 295-303. https://doi.org/10.1016/j.ijbiomac.2020.01.074

Sharmila, G., Muthukumaran, C., Manoj Kumar, N., Sivakumar, V. M., \& Thirumarimurugan, M. (2020). Current Developments in Biotechnology and Bioengineering. Food waste valorization for biopolymer production, 233-249. https://doi.org/10.1016/B978-0-444-64321-6.00012-4

Shen, M, Song, B, Zeng, Guangming, Z, Yaxin, H, W, Wen, X, \& Tang, W. (2020). Are biodegradable plastics a promising solution to solve the global plastic pollution? Environmental Pollution, 263, 114469. https://doi.org/10.1016/j.envpol.2020.114469

Shogren, R., Wood, D., Orts, W., \& Glenn, G. (2019). Plant-based materials and transitioning to a circular economy. Sustainable Production and Consumption, 19, 194-215. https://doi.org/10.1016/j.spc.2019.04.007

Silva, A. L. P., Prata, J. C., Walker, T. R., Duarte, A. C., Ouyang, W., Barcelò, D., \& Rocha-Santos, T. (2021). Increased plastic pollution due to COVID-19 pandemic: challenges and recommendations. Chemical Engineering Journal, 405, 126683. https://doi.org/10.1016/j.cej.2020.126683

Silva, A. P. M., Oliveira, A. V., Pontes, S. M. A., Pereira, A. L. S., Filho, M. S. M. S., Rosa, M. F., Azeredo, H. M. C. (2019). Mango kernel starch films as affected by starch nanocrystals and cellulose nanocrystals. Carbohydrate Polymers, 211, 209-216. https://doi.org/10.1016/j.carbpol.2019.02.013

Silva, L. M. R. D., Figueiredo, E. A. T. D., Ricardo, N. M. P. S., Vieira, I. G. P., Figueiredo, R. W. D., Brasil, I. M., \& Gomes, C. L. (2014). Quantification of bioactive compounds in pulps and by-products of tropical fruits from Brazil. Food Chemistry, 143, 398-404. https://doi.org/ 10.1016/j.foodchem.2013.08.001.

Silva, M. L. T., Brinques, G. B., \& Gurak, P. D. (2020c). Development and characterization of corn starch bioplastics containing dry sprout by-product flour. Brazilian Journal of Food Technology, 23, e2018326. https://doi.org/10.1590/1981-6723.32618

Silva, S. M. F., Ribeiro, H. L., Mattos, A. L. A., Borges, M. F., Rosa, M. F., \& Azeredo, H. M. C. (2020a). Films from cashew byproducts: cashew gum and bacterial cellulose from cashew apple juice. Journal of Food Science and Technology, 58, 1979-1986. https://doi.org/10.1007/s13197-020-04709-7

Silva, V. D. M., Macedo, M. C. C., Rodrigues, C. G., Santos, A. N., Loyola, A. C. F., \& Fante, C. A. (2020b). Biodegradable edible films of ripe banana peel and starch enriched with extract of Eriobotrya japonica leaves. Food Bioscience, 38, 100750. https://doi.org/10.1016/j.fbio.2020.100750

Sogut, E., \& Cakmak, H. (2020). Utilization of carrot (Daucus carota L.) fiber as a filler for chitosan-based films. Food Hydrocolloids, 106, 105861. https://doi.org/10.1016/j.foodhyd.2020.105861

Soofi, M., Alizadeh, A., Hamishehkar, H., Almasi, H., \& Roufegarinejad, L. (2021). Preparation of nanobiocomposite film based on lemon waste containing cellulose nanofiber and savory essential oil: A new biodegradable active packaging system. International Journal of Biological Macromolecules, 169, 352-361. https://doi.org/10.1016/j.ijbiomac.2020.12.114

Sousa, M. S. B., Vieira, L. M., Silva, M. J. M., \& Lima, A. (2011). Caracterização nutricional e compostos antioxidantes em resíduos de polpas de frutas tropicais. Ciência e Agrotecnologia, 35(3), 554-559. https://doi.org/10.1590/S1413-70542011000300017.

Souza, E., Gottschalk, L., \& Freitas-Silva, O. (2020b). Overview of nanocellulose in food packaging. Recent Patents on Food, Nutrition \& Agriculture, 10. https://doi.org/10.2174/2212798410666190715153715

Souza, F. R. A., Oliveira, J. S. T., Silva, D. P., Oliveira, M. G., Neves, D. D., Silva, W. E., \& Stamford, T. C. M. (2021). Biopolímeros na indústria de alimentos: do aproveitamento de resíduos agroindustriais a produção de biopolímeros. Avanços em Ciência e Tecnologia de Alimentos, 4 (pp. $370-388$ ), Editora Científica Digital.

Souza, P. G., Santos, S. F., Nogueira, T. B. B., Santana, I., Fai, A. E. C. (2020a). Avaliação de desperdício em restaurantes comerciais do tipo self-service total na Universidade do Estado do Rio de Janeiro (UERJ). Research, Society and Development, 9(6), e167963605. https://doi.org/10.33448/rsd-v9i6.3605

Suriyatem, R., Auras, R. A., \& Rachtanapun, P. (2018). Improvement of mechanical properties and thermal stability of biodegradable rice starch-based films blended with carboxymethyl chitosan. Industrial Crops and Products, 122, 37-48. https://doi.org/10.1016/j.indcrop.2018.05.047

Takeyama, M. M., Kawaguti, H. Y., Koblitz, M. G. B., \& Fai, A. E. C. (2020). Agroindustrial wastes as promising raw materials for obtaining yeast bioproducts - a brief review. [Resíduos agroindustriais como insumos promissores para obtenção de bioprodutos por

leveduras - uma breve revisão]. Research, Society and Development, 9(7), e588974488.

Tako, Y., Matheus, J. R. V., \& Fai, A. E. C. (2021). Economia circular para repensar as embalagens: uma breve revisão. Interfaces entre Desenvolvimento, Meio Ambiente e Sustentabilidade 2. Atena. https://doi.org/10.22533/at.ed.571211503

Teigiserova, D. A., Hamelin, L., \& Thomsen, M. (2019). Review of high-value food waste and food residues biorefineries with focus on unavoidable wastes from processing. Resources, Conservation \& Recycling, 149, 413-426. https://doi.org/10.1016/j.resconrec.2019.05.003

Tencati, A., Pogutz, S., Moda, B., Brambilla, M., \& Cacia, C. (2016). Prevention policies addressing packaging and packaging waste: Some emerging trends. Waste Management, 56, 35-45. 
Research, Society and Development, v. 10, n. 9, e49210918278, 2021

(CC BY 4.0) | ISSN 2525-3409 | DOI: http://dx.doi.org/10.33448/rsd-v10i9.18278

Theivasanthi, T., Anne Christma, F. L., Toyin, A. J., Gopinath, S. C. B., \& Ravichandran, R. (2018). Synthesis and characterization of cotton fiber-based nanocellulose. International Journal of Biological Macromolecules, 109, 832-836. https://doi.org/10.1016/j.ijbiomac.2017.11.054

Tibolla, H., Feltre, G., Sartori, T., Czaikoski, A., Pelissari, F.M., Menegalli, F.C., \& Cunha, R.L. (2020). Shelf life of cashew nut kernels packed in banana starch-based nanocomposites. International Journal of Food Science \& Technology. https://doi.org/10.1111/ijfs.14920

Tirado-Gallegos, J. M., Zamudio-Flores, P. B., Ornelas-Paz, J. J., et al. (2018). Elaboration and characterization of active apple starch films incorporated with ellagic acid. Coatings, 8(11), 384. https://doi.org/10.3390/coatings8110384

Tosati, J. V., Messias, V. C., Carvalho, P. I. N., Pollonio, M. A. R., Meireles, M. A. A., \& Monteiro, A. R. (2017). Antimicrobial effect of edible coating blend based on turmeric starch residue and gelatin applied onto fresh frankfurter sausage. Food and Bioprocess Technology, 10, $2165-2175$. https://doi.org/10.1007/s11947-017-1985-1

Travalini, A. P., Lamsal, B., Magalhães, W. L. E., \& Demiate, I. M. (2019). Cassava starch films reinforced with lignocellulose nanofibers from cassava bagasse. International Journal of Biological Macromolecules, 139, 1151-1161. https://doi.org/10.1016/j.ijbiomac.2019.08.115

UNEP. (2018). Single-use plastics: a roadmap for sustainability. 〈https://www.unep.org/resources/report/single-use-plastics-roadmap-sustainability> .

UNEP. (2021). Food waste index report. Disponível em: <https://drive.google.com/file/d/1KTB1mq9sSWXx38bDfvF0PQy0sEKYsgrn/view>. Acesso em: 13 de maio de 2021.

Velarde, E. D. A., Martínez, D. L. P., Salem, A. Z. M., García, P. G. M., \& Berasain, M. D. M. (2020). Antioxidant and antimicrobial capacity of three agroindustrial residues as animal feeds. Agroforestry Systems, 94, 1393-1402. https://doi.org/10.1007/s10457-018-00343-7

Velenturf, A. P. M., \& Purnell, P. (2021). Principles for a sustainable circular economy. Sustainable Production and Consumption, $27,1437-1457$. https://doi.org/10.1016/j.spc.2021.02.018

Vidal, O. L., Tsukui, A., Garrett, R., Rocha-Leão, M. H. M., Carvalho, C. W. P., Freitas, S. P., Rezende, C. M., \& Ferreira, M. S. L. (2019). Production of bioactive films of carboxymethyl cellulose enriched with green coffee oil and its residues. International Journal of Biological Macromolecules, 146, 730-738. https://doi.org/10.1016/j.ijbiomac.2019.10.123

Wang, L. F., Shankar, S., \& Rhim, J. W. (2017). Properties of alginate-based films reinforced with cellulose fibers and cellulose nanowhiskers isolated from mulberry pulp. Food Hydrocolloids, 63, 201-208. https://doi.org/10.1016/j.foodhyd.2016.08.041

Willett, W., Rockström, J., Loken, B., et al. (2019). Food in the Anthropocene: the EAT-Lancet commission on healthy diets from sustainable food systems. Lancet, 393, 447-492. https://doi.org/10.1016/S0140-6736(18)31788-4

Wróblewska-Krepsztul, J., Rydzkowski, T., Borowski, G., Szczypiński, M., Klepka, T., \& Thakur, V. K. (2018). Recent progress in biodegradable polymers and nanocomposites-based packaging materials for sustainable environment. International Journal of Polymer Analysis and Characterization, 23(4), 383-395. https://doi.org/10.1080/1023666X.2018.1455382

Yepes, O. O., Di Giogio, L., Goyanes, S., Mauri, A., Famá, L. (2019). Influence of process (extrusion/thermo-compression, casting) and lentil protein content on physicochemical properties of starch films. Carbohydrate Polymers, 208, 221-231. https://doi.org/10.1016/j.carbpol.2018.12.030

Zheng, J., \& Suh, S. (2019). Strategies to reduce the global carbon footprint of plastics. Nature Climate Change, 9(5), 374-378. https://doi.org/10.1038/s41558019-0459-z

Zuin, V. G., \& Ramin, L. Z. (2018). Green and sustainable separation of natural products from agro-industrial waste: challenges, potentialities, and perspectives on emerging approaches. Topics in Current Chemistry, 376(3), 1-54. https://doi.org/10.1007/s41061-017-0182-z 